\title{
Microfósseis não polínicos como indicadores de mudanças ambientais no Holoceno médio da Lagoa Comprida, Parque Nacional da Restinga de Jurubatiba, Estado do Rio de Janeiro, Brasil
}

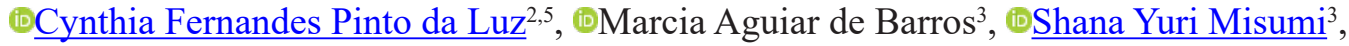

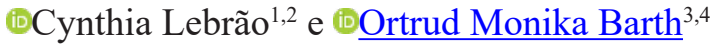

Recebido: 19 agosto 2018; aceito: 7 março 2019

Como citar: Luz, C.F.P., Barros, M.A., Misumi, S.Y., Lebrão, C. \& Barth, O.M. 2019. Microfósseis não polínicos como indicadores de mudanças ambientais no Holoceno médio da Lagoa Comprida, Parque Nacional da Restinga de Jurubatiba, Estado do Rio de Janeiro, Brasil. Hoehnea 46: e782018. http://dx.doi.org/10.1590/2236-8906-78/2018.

\begin{abstract}
Non-pollen microfossils as indicators of environmental changes in the middle Holocene of the Lagoa Comprida, Parque Nacional da Restinga de Jurubatiba, Rio de Janeiro State, Brazil). The aim of this work was to identify and describe the morphology of non-pollen microfossils present in the sediments of a core collected near the Lagoa Comprida barrier, Rio de Janeiro State, Brazil. Eight forms of fungi, two types of Chlorococcales algae at the colonial stage, one zygospore of Zygnematales, four of diatoms, one of microforaminifer, two cysts of dinoflagellates, one spicule of Porifera, one spore of bryophyte, and nine spores of ferns and lycophytes were identified. Ecological information on the organisms of origin was given to provide reference material for paleoenvironmental reconstruction along the Holocene in restinga areas. Keywords: Algae, fern spores, fungi, palynological analysis
\end{abstract}

RESUMO - (Microfósseis não polínicos como indicadores de mudanças ambientais no Holoceno médio da Lagoa Comprida, Parque Nacional da Restinga de Jurubatiba, Estado do Rio de Janeiro, Brasil). O trabalho teve como objetivo identificar e descrever a morfologia de microfósseis não polínicos ocorrentes nos sedimentos de um testemunho retirado próximo à barra da Lagoa Comprida, Estado do Rio de Janeiro, Brasil. Foram identificadas oito formas de fungos, dois tipos de algas Chlorococcales em estágio colonial, um tipo de zygósporo de alga Zygnematales, quatro de diatomáceas, um de microforaminífero, dois de cistos de dinoflagelados, um de microesclera de Porifera, um de esporo de briófita e nove de esporos de samambaias e licófitas. Informações ecológicas sobre os organismos de origem foram fornecidas para prover material de referência para a reconstrução paleoambiental ao longo do Holoceno em áreas de restinga.

Palavras-chave: Algas, análise palinológica, esporos de samambaias, fungos

\section{Introdução}

Os microfósseis fazem parte de um grupo heterogêneo que inclui organismos (ou seus restos) de diferentes grupos taxonômicos, todos com tamanho reduzido (microscópico). A análise palinológica é um excelente instrumento investigativo, pois esporos de samambaias e licófitas, assim como outros componentes locais não polínicos, geralmente são abundantes no depósito sedimentar de lagos e turfeiras e muito resistentes ao intemperismo. Esses microfósseis não polínicos, quando adequadamente sedimentados, podem fossilizar, revelando estágios pretéritos da vegetação aquática e adjacente (Campbell 1991, Seppa \& Bennett 2003).

Em relação aos componentes locais (autóctones), assume-se que muitos dos esporos de briófitas, licófitas e samambaias depositados em sedimentos lacustres derivam de plantas hidrófitas que crescem no entorno do lago. A dispersão dos esporos de licófitas e samambaias favorece o estabelecimento de novas populações de plantas, sendo cruciais na

1. Parte da Dissertação de Mestrado da quarta Autora

2. Instituto de Botânica, Núcleo de Pesquisa em Palinologia, Avenida Miguel Stéfano, 3.687, 04301-902 São Paulo, SP, Brasil

3. Universidade Federal do Rio de Janeiro, Departamento de Geologia, Laboratório de Palinologia, CCMN, J2-19, Ilha do Fundão, 21949-900 Rio de Janeiro, RJ, Brasil

4. Instituto Oswaldo Cruz, Fiocruz, Departamento de Virologia, Avenida Brasil, 4365, 21045-900 Rio de Janeiro, RJ, Brasil

5. Autora para correspondência: cyluz@yahoo.com.br 
sucessão ecológica e nos processos de restauração ambiental. São capazes de colonizar áreas perturbadas e contribuem para a manutenção da umidade local, desempenhando papel importante para a sobrevivência de diversos grupos vegetais que se sucedem nas áreas por elas inicialmente colonizadas (Brade 1940, Sota 1971, Groot et al. 2011, Groot et al. 2012). Esses esporos geralmente são sub-representados espacialmente no depósito sedimentar de um lago devido em parte a suas maiores dimensões que causam deposição diferencial no fundo conforme proximidade da planta-mãe e batimetria (Luz et al. 2005, Luz 2012, Luz 2013).

Outros componentes locais incluem os fungos fósseis que podem fornecer inferências sobre as plantas hospedeiras (van Hoeve \& Hendrikse 1998), assim como as algas microscópicas, espículas de esponja e outros microfósseis (Jansonius \& Mcgregor 1996).

Em depósitos lacustres os restos fúngicos são raros, sendo geralmente encontrados em conjunto com restos das plantas hospedeiras ou em restos vegetais carbonizados (Van Geel 2001). Acreditava-se que em ambientes aquáticos não havia produção estritamente local de esporos de fungos que pudessem se preservar no depósito. Porém, nos últimos anos verificou-se que os hifomicetos aquáticos e outras formas terrestres filamentosas, que necessitam de um substrato sólido, exclusivamente usam a coluna de água para dispersão de seus propágulos, enquanto que as leveduras são potencialmente encontradas em todos os lugares, inclusive na zona pelágica. Muitos fungos filamentosos possuem esporos que são adaptados para a dispersão em água corrente, fixados a detritos vegetais, tais como folhas (Wurzbacher et al. 2010). Normalmente, os esporos de fungos são fossilizados perto do local onde ocorreu a esporulação e somente os maiores e de parede grossa se fossilizam, já que os menores e de parede fina são facilmente dispersos para a atmosfera (Van Geel 2001).

Dentre as algas microscópicas, as diatomáceas respondem rapidamente às alterações ambientais e apresentam diferentes amplitudes ecológicas, permitindo relacionar as espécies com a salinidade e temperatura. Por isso, caracterizam-se como excelentes bioindicadores das condições ambientais em escala temporal, já que suas frústulas silicosas permanecem bem preservadas nos sedimentos (Belling et al. 2006, Bennion \&Simpson 2011).

As algas microscópicas coloniais (cenóbios) da ordem Chlorococcales e zigósporos de Zygnematales são os microfósseis mais abundantes encontrados em sedimentos de lagos e pântanos devido à sua parede externa resistente pela presença de esporopolenina. $\mathrm{O}$ número de células individuais dos cenóbios de algumas algas reflete a condição ambiental durante o processo reprodutivo e, o tamanho do cenóbio reflete as condições durante o estado vegetativo (Brenner \& Foster 1994). Em algumas espécies há também um tipo de reprodução vegetativa onde as células somáticas podem mudar, adicionando uma parede espessa. Essas células podem funcionar como esporos de resistência (cistos), que ficam dormentes durante os períodos hostis enquanto todas as outras células somáticas morrem (Brenner \& Foster 1994, Jansonius \& Mcgregor 1996).

Tipicamente marinhos, com poucas espécies em águas dulceaquícolas, os dinoflagelados e microforaminíferos geralmente indicam ambientes de elevada salinidade e conexão com o oceano e/ ou influenciados pela maré. Podem ser usados para caracterizar ciclos de transgressão-regressão, distância da linha de costa e curva eustática (Traverse 1988, Medeanic et al. 2007). Os dinoflagelados, com 1.348 táxons no Brasil, são organismos unicelulares biflagelados com ciclo de vida que permite habitar, alternativamente, o plâncton (como células vegetativas móveis) e o bento (como cistos imóveis) (Cardoso \& Torgan 2007, Bicudo \& Menezes 2010). Da mesma forma, os microforaminíferos tanto podem ser planctônicos quanto bentônicos. Os principais morfogrupos são representados por câmaras simples, unisseriais, bisseriais ou espiraladas, sendo frequentes nos sedimentos holocênicos correspondentes ao máximo da transgressão marinha (Lorscheitter 1983, Medianic et al. 2001).

Conforme Volkmer-Ribeiro \& Pauls (2000) as esponjas são organismos exclusivamente aquáticos e bentônicos, que vivem presos a um substrato firme, encontrados tanto em águas continentais quanto marinhas e, cuja presença reflete a qualidade da água, uma vez que são filtradores e não toleram grandes concentrações de sedimentos dissolvidos.

Todas essas formas são depositadas diferencialmente no fundo de um lago conforme a batimetria, direção dos ventos e presença de correntes. Sendo assim, qualquer mudança temporal nas concentrações desses componentes locais em um registro sedimentar pode indicar variações no volume de água e nos aspectos hidrológicos de um lago, evidenciando a dinâmica resultante de distúrbios na sucessão ecológica, tanto da vegetação localizada em 
sua margem quanto da vegetação aquática (Luz et al. 2002, Luz et al. 2005, Luz 2012, 2013).

A correta identificação dos microfósseis não polínicos, associando-os às inferências ecológicas correspondentes às suas formas de vida, é imprescindível para os estudos de Palinologia do Quaternário. Portanto, torna-se importante obter uma base de dados morfológicos e ecológicos dos microfósseis não polínicos recuperados de sedimentos lacustres em área de restinga para a reconstrução paleoambiental costeira.

O objetivo principal do presente trabalho é descrever os táxons não polínicos encontrados no registro palinológico obtido de um testemunho coletado na região da barra da Lagoa Comprida, Parque Nacional da Restinga de Jurubatiba, fornecendo material de referência para estudos paleoambientais no litoral norte do Estado do Rio de Janeiro.

\section{Material e métodos}

Área de Estudo - O Parque Nacional da Restinga de Jurubatiba (PARNA da Restinga de Jurubatiba) está localizado na costa norte do Estado do Rio de Janeiro, abrangendo as planícies fluvial e marinha de parte dos municípios de Carapebus, Macaé e Quissamã, incluindo uma área de 14.919,46 hectares (figura 1). O PARNA de Jurubatiba é o único Parque Nacional criado no Brasil com o objetivo específico de proteger a formação de restinga e representa a maior área desse ambiente protegida por lei federal (Dec s/no de 29 de abril de 1998) a compreender exclusivamente esse ecossistema (Rocha et al. 2004, IBAMA 2007, Caris et al. 2013).

Entre o município de Macaé e a Barra do Furado (município de Quissamã), o litoral do PARNA de Jurubatiba é caracterizado por um terraço pleistocênico bem desenvolvido e composto por uma série de cristas paralelas de praia, com um estreito cordão litorâneo formado no último evento transgressivo marinho do Pleistoceno, a cerca de 123.000 anos A.P. Esse terraço pleistocênico não sofreu afogamento durante a última transgressão holocênica em cerca de 5.100 anos A.P. (5.600 cal anos A.P.), caracterizando-se como uma zona de não-deposição ou de trânsito dos sedimentos holocênicos arenosos carreados pela deriva litorânea sob condições hidrodinâmicas de ondas eficazes do setor sul em direção ao norte (Martin et al. 1984, Martin et al. 1993, Martin et al. 1997, Caris et al. 2013).

No PARNA de Jurubatiba existem 18 sistemas lagunares que foram, no passado, isolados do mar por ilhas barreiras. $\mathrm{O}$ aspecto truncado das margens lagunares, em contato com o reverso do cordão litorâneo e, a presença de cúspides internas, sugere que as lagunas eram mais largas do que a configuração atual (Dias \& Silva 1984). A Lagoa Comprida, que se localiza no município de Macaé, é uma dessas lagunas formadas após o último evento transgressivo marinho do Pleistoceno (Martin et al. 1997, Plano de Manejo do Parque Nacional da Restinga de Jurubatiba 2007).

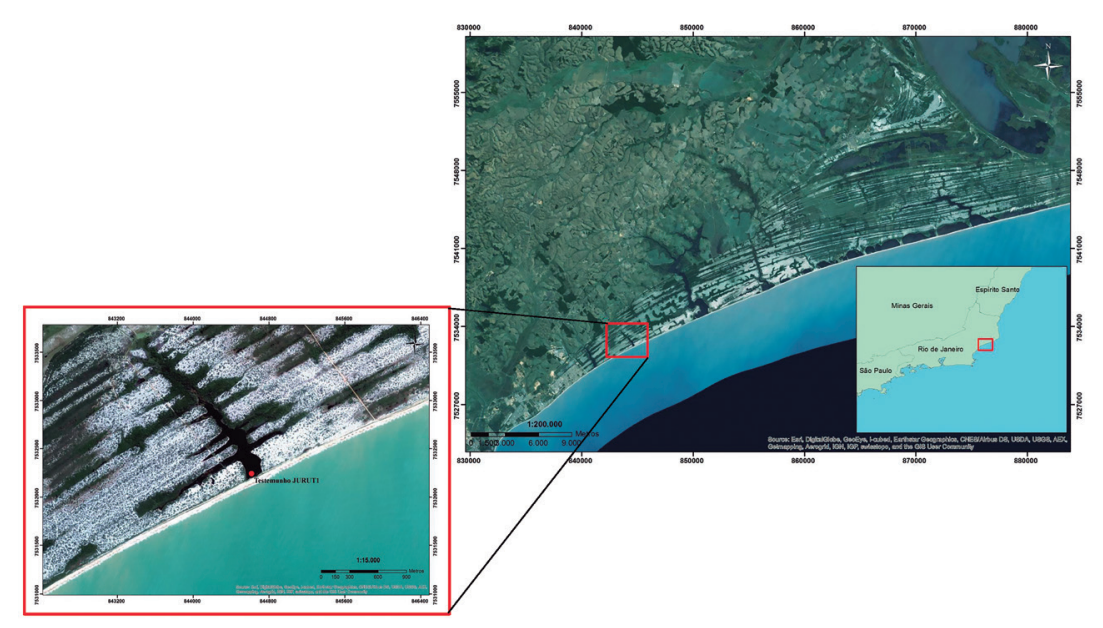

Figura 1. Mapa de localização do Parque Nacional da Restinga de Jurubatiba, Rio de Janeiro, Brasil, e da Lagoa Comprida (demarcada pelo quadrado vermelho). O ponto vermelho representa o local de retirada do testemunho JURU T1 na barra da Lagoa Comprida. Fonte: Acervo do Núcleo de Pesquisa em Palinologia.

Figure 1. Map of Jurubatiba Sandbank National Park, Rio de Janeiro, Brazil, and Lagoa Comprida (demarcated by the red square). The red dot represents the prospection place of the JURU T1 core in the bar of Lagoa Comprida. Source: Collection of the Núcleo de Pesquisa em Palinologia. 
A Lagoa Comprida com cerca de $0,13 \mathrm{~km}^{2}$ apresenta profundidade média de $1,9 \mathrm{~m}$ e é um sistema de águas doces a raramente oligohalino, com salinidade média de $0,4 \mu \mathrm{S}, \mathrm{pH}$ ácido de 5,5 relacionado à maior concentração de compostos húmicos e fúlvicos em suas águas muito escuras (Dias et al. 2001, EnrichPrast et al. 2004, Caliman et al. 2010). Na atualidade a Lagoa Comprida pode sofrer intrusões marinhas devido à baixa variabilidade topográfica entre a praia e a antepraia (Muehe 2004, Caliman et al. 2010).

A vegetação atual da área foi caracterizada em dez comunidades por Araujo et al. (1998) como halófila-psamófila reptante, herbácea brejosa, arbustiva fechada de pós-praia, arbustiva aberta de Clusia, arbustiva aberta de Ericaceae, arbustiva aberta de Palmae, mata permanentemente inundada, mata periodicamente inundada, mata de cordão arenoso e vegetação aquática. Dentre essas, apenas as formações abertas de Clusia e de Ericaceae e a mata periodicamente inundada foram estudadas com mais detalhes (Araujo et al. 2004). O conhecimento sobre a flora da área foi sintetizado em Araujo et al. (2004), especialmente com relação à formação aberta de Clusia, que ocupa $40 \%$ da área total do PARNA de Jurubatiba. A riqueza de licófitas e samambaias do Parque Nacional da Restinga de Jurubatiba foi publicada por Santos \& Sylvestre (2001) e Santos et al. (2004) e a de briófitas por Imbassahy et al. (2009). As algas da Lagoa Comprida foram analisadas em Huszar \& Esteves (1988), Melo \& Suzuki (1998), Dias et al. (2001) e Alves-de-Souza et al. (2006).

Procedimentos de coleta do testemunho e datação radiocarbônica - Um testemunho de mergulho (JURU T1) de $153 \mathrm{~cm}$ de comprimento foi retirado da borda sudeste da Lagoa Comprida (22 $16^{\prime} 52^{\prime}$ 'S, $41^{\circ} 39^{\prime} 22^{\prime \prime} \mathrm{W}$ ), próximo à sua barra, utilizando o método manual de percussão (figura 1). A cronologia dos eventos ambientais foi obtida em sete níveis sedimentares pelo Método Absoluto de Datação Radiométrica do ${ }^{14} \mathrm{C}$ (Carbono 14) utilizando-se Espectrometria de Massas com Aceleradores (AMS) no laboratório Beta Analytic (Flórida/EUA).

Procedimentos laboratoriais de preparação das lâminas de microscopia - O presente catálogo baseia-se na análise palinológica de quinze níveis sedimentares que foram amostrados no Departamento de Geologia da Universidade Federal do Rio de Janeiro, retirando-se $8 \mathrm{~cm}^{3}$ de sedimento, em intervalos de $10 \mathrm{em} 10 \mathrm{~cm}$ (ou de acordo com as mudanças litológicas). As quinze amostras selecionadas corresponderam às seguintes profundidades: $147-149 \mathrm{~cm}$ (base), $137-139 \mathrm{~cm}$, $128-130 \mathrm{~cm}, 117-119 \mathrm{~cm}, 107-109 \mathrm{~cm}, 97-99 \mathrm{~cm}$, $87-89 \mathrm{~cm}, 77-79 \mathrm{~cm}, 66-68 \mathrm{~cm}, 57-59 \mathrm{~cm}, 47-49 \mathrm{~cm}$, $36-38 \mathrm{~cm}, 27-29 \mathrm{~cm}, 19-20 \mathrm{~cm}$ e $08-10 \mathrm{~cm}$ (topo). O processamento químico das amostras foi realizado no Núcleo de Pesquisa em Palinologia (NPP) do Instituto de Botânica em São Paulo e segundo a metodologia de preparação para sedimentos do Quaternário proposta por Ybert et al. (1992), com modificações. Foram introduzidas cinco pastilhas de Lycopodim clavatum por amostra, com posterior tamisação por malha de $250 \mu \mathrm{m}$. O material sofreu desidratação por ácido acético glacial e, em sequência, foi acetolisado. Os microfósseis foram separados da matriz sedimentar pela tamisação por malha de $5 \mu \mathrm{m}$ em banho de ultrassom. Não foi utilizado o ácido fluorídrico a $40 \%$, já que os sedimentos não apresentaram areia, e objetivou-se a recuperação de diatomáceas e microescleras de poríferos do material. Para a montagem das lâminas de microscopia utilizou-se gelatina glicerinada (Kisser 1935 apud Erdtman 1952), selando-as com parafina. As análises palinológicas foram realizadas em microscópio óptico Olympus BX50 e as lâminas foram depositadas na palinoteca do NPP.

Identificação, descrição, ilustração dos microfósseis e tratamento estatístico dos dados - A identificação dos esporos das samambaias, licófitas e briófitas se deu através do método comparativo com seus equivalentes modernos da coleção de referência (palinoteca) do NPP e com bibliografia específica (Tryon \& Tryon 1982, Tryon \& Lugardon 1990, van Hoeve \& Hendrikse 1998, Luz \& Barth 2002, Freitas \& Carvalho 2012). Bibliografia específica também foi utilizada para a identificação das diatomáceas (Moreira-Filho \& Moreira 1984), algas Chlorococcales e Zygnematales (van Geel 1976, van Geel \& van Der Hammen 1978, van Hoeve \& Hendrikse 1998, Luz et al. 2002), fungos (van Hoeve \& Hendrikse 1998, Jansonius \& Kalgutkar 2000, Kalgutkar \& Jansonius 2000, Freitas \& Carvalho 2011), cistos de dinoflagelados (Marret \& Zonneveld 2003) e microforaminíferos (Stancliffe 1989). A identificação da microesclera de porífero foi confirmada por especialistas (Parolin, M. e Silva, K.C., comunicação pessoal), assim como a dos microforaminíferos (Vilela, C.G. e Cardoso, M.N., comunicação pessoal). A identificação dos microfósseis foi feita na categoria taxonômica de menor nível hierárquico sempre que possível. A denominação "Tipo" foi empregada quando não 
foi possível assegurar o grau taxonômico, já que espécies afins, variedades e subespécies dentro de uma espécie podem ter tipos morfológicos iguais (Berglund 1986, Salgado-Labouriau 2007). Dentro dos grandes grupos taxonômicos foi mantida a ordem alfabética por gêneros. A descrição dos microfósseis não polínicos foi feita com base em suas características morfológicas, empregando-se terminologia específica (Barth \& Melhem 1988, Stancliffe 1989, Elsik 1992, Lellinger 2002, Bicudo \& Menezes 2006, Punt et al. 2007). A captura das imagens foi feita pela câmera digital Olympus U-CMAD-2 acoplada ao microscópio óptico utilizando-se o programa CellSens Standard 1.5 para Windows versão 2011. A frequência de ocorrência foi calculada mediante o número de vezes que um determinado microfóssil não polínico ocorreu (presença) dividindo-se pelo total de amostras analisadas. Para o cálculo das concentrações das algas, esporos de briófitas, samambaias, licófitas e microforaminíferos houve a contagem paralela aos 500 grãos de pólen por amostra, ou até a saturação, com no mínimo 100 esporos marcadores de Lycopodium clavatum contados (Lorscheitter \& Roth 2013). Fungos, dinoflagelados e espículas de poríferos não foram incluídos nos cálculos de concentração, sendo apenas registradas suas presenças nos níveis estratigráficos.

Avaliação ambiental da assembléia microfossilíferaEstudos contemporâneos no PARNA de Jurubatiba associaram condições ambientais específicas como oligotrofia, grau de dessecamento, temperatura, salinidade e grau de inundação em inselbergs com Clusia, em área seca da restinga, em área úmida da restinga e na floresta semidecídua (Araújo 2000, Scarano et al. 2005). Os tipos de esporos de samambaias, licófitas e briófitas foram alocados nas formações vegetais de Araujo et al. (1998) onde ocorrem atualmente no PARNA de Jurubatiba ou especialmente no entorno da Lagoa Comprida (Santos \& Sylvestre 2001, Santos et al. 2004, Bove \& Paz 2009, Imbassahy et al. 2009). Para a avaliação ambiental dos fungos utilizou-se os trabalhos de Elsik (1996), Kalgutkar \& Jansonius (2000) e Jansonius \& Kalgutkar (2000); para as algas Chlorococcales e Zygnematales os trabalhos de Van Geel (1978), Hooghiemstra (1984), Huszar \& Esteves (1988), Jansonius \& Mcgregor (1996), Melo \& Suzuki (1998), Dias et al. (2001), Alves-de-Souza et al. (2006), Bicudo \& Menezes (2006) e Bicudo (2012); para as diatomáceas os trabalhos de Huszar \& Esteves (1988),
Round et al. (1990), Dias et al. (2001), McQuoida \& Nordberg (2003), Pacheco et al. (2016) e Guiry \& Guiry (2018); para os cistos de dinoflagelados foram utilizados os trabalhos de Dale (1996, 2001), Marret \& Zonneveld (2003), Souza (2012) e Santos et al. (2017); para os microforaminíferos os trabalhos de Pedrão \& Carvalho (2002), Duleba et al. (2005) e Salgado-Labouriau (2007). Informações ambientais sobre a ocorrência das microescleras de poríferos foram fornecidas primeiramente pelos especialistas consultados, sendo posteriormente consultados os trabalhos de Silva et al. (2009) e Volkmer-Ribeiro \& Parolin (2010).

\section{Resultados}

A descrição sedimentológica do testemunho foi realizada pela equipe do Laboratório de Geologia Sedimentar (LAGESED) do Departamento de Geologia da Universidade Federal do Rio de Janeiro conforme a granulometria, cor dos sedimentos, conteúdo macroscópico de restos vegetais e presença de raízes (tabela 1). A datação radiométrica por ${ }^{14} \mathrm{C}$ na base do testemunho JURU T1 da barra da Lagoa Comprida foi de $6.140+/-40{ }^{14} \mathrm{C}$ anos AP (6.915 cal anos AP) e a do topo foi de $5.710+/-40{ }^{14} \mathrm{C}$ anos AP (6.490 cal anos AP), relacionando-se ao Holoceno médio e, indicando que a sequência temporal representou 430 anos de sedimentação (tabela 2).

Foram identificadas oito formas de fungos, dois tipos de algas Chlorococcales em estágio colonial, um de zygósporo de alga Zygnematales, quatro de diatomáceas, um de microforaminífero, dois de cistos de dinoflagelados, um de microesclera de Porifera, um de esporo de briófita e nove de esporos de samambaias e licófitas. Durante o intervalo de tempo analisado as maiores frequências de ocorrência se deram com relação aos esporos de samambaias, respectivamente, Serpocaulon, Blechnum e Pteridium, seguidos dos fungos, e componentes aquáticos das diatomáceas e microforaminíferos (figura 2). Com base nos levantamentos florísticos de Bove \& Paz (2009), Imbassahy et al. (2009), Santos \& Sylvestre (2001) e Santos et al. (2004), os esporos de briófitas, licófitas e samambaias dos sedimentos da Lagoa Comprida provavelmente tiveram suas origens principalmente na vegetação das fitofisionomias "Mata Periodicamente Inundada", "Herbácea brejosa", "Áreas Alteradas" e "Mata Permanentemente Inundada", com menor representatividade da "Arbustiva Fechada de Pós-Praia”. Os esporos da vegetação aquática 
Tabela 1. Descrição sedimentológica do testemunho JURU T1 (Lagoa Comprida, Parque Nacional de Jurubatiba - PARNA Jurubatiba - Macaé, RJ), conforme a granulometria, cor dos sedimentos, conteúdo macroscópico de restos vegetais e presença de raízes.

\begin{tabular}{|c|c|}
\hline Profundidade $(\mathrm{cm})$ & Sedimentologia \\
\hline 0 a 65 & $\begin{array}{l}\text { Material lamoso, rico em matéria orgânica (fragmentos de vegetais), com presença de raízes, cor } \\
\text { castanho escuro. Presença de areia grossa, subarredondada a arredondada (dois primeiros centímetros } \\
\text { do topo do testemunho). Presença de poucas raizes finas entre } 0-20 \mathrm{~cm} \text {. }\end{array}$ \\
\hline 65 a 75 & Material argiloso com matéria orgânica, cor cinza escuro. Presença de poucas raízes finas. \\
\hline 75 a 99 & $\begin{array}{c}\text { Material lamoso rico em matéria orgânica (fragmentos de vegetais), cor castanho escuro. Presença de } \\
\text { poucas raízes finas. }\end{array}$ \\
\hline 99 a 120 & $\begin{array}{c}\text { Material argiloso com matéria orgânica (fragmentos de vegetais), cor cinza escuro. Presença de poucas } \\
\text { raízes finas. }\end{array}$ \\
\hline 120 a 130 & $\begin{array}{c}\text { Material argiloso com fragmentos de vegetais dispersos, cor cinza médio. Presença de poucas raízes } \\
\text { finas. }\end{array}$ \\
\hline 130 a 153 & $\begin{array}{c}\text { Material argiloso com maciço, fragmentos grandes de vegetais, cor cinza médio. Presença de poucas } \\
\text { raízes finas entre } 145-153 \mathrm{~cm} .\end{array}$ \\
\hline
\end{tabular}

Tabela 2. Datações ${ }^{14} \mathrm{C}$ anos AP e cal anos AP $(2 \sigma=95 \%)$ do testemunho JURU T1 (Lagoa Comprida, Parque Nacional de Jurubatiba - PARNA Jurubatiba - Macaé, RJ).

\begin{tabular}{|c|c|c|c|c|c|}
\hline $\begin{array}{l}\text { Código do } \\
\text { laboratório }\end{array}$ & ${ }^{14} \mathrm{C}(\operatorname{anos} \mathrm{AP})$ & $\begin{array}{l}\text { Anos calibrados (cal } \\
\text { anos AP) (média do } \\
\text { intervalo) }\end{array}$ & ${ }^{13} \mathrm{C} /{ }^{12} \mathrm{C}$ & $\begin{array}{l}\text { Profundidade } \\
\quad(\mathrm{cm})\end{array}$ & Material \\
\hline $\begin{array}{l}\text { Beta - 322813 } \\
\text { (JURUT1-4) }\end{array}$ & $5.710+/-40$ & $\begin{array}{c}6.570 \text { a } 6,410 \\
(6.490)\end{array}$ & $-26.3 \%$ & $27-29$ & Sedimento orgânico \\
\hline $\begin{array}{l}\text { Beta - 399322 } \\
\text { (JURUT1-7) }\end{array}$ & $5.890+/-30$ & $\begin{array}{c}6.580 \text { a } 6,570 \\
(6.575)\end{array}$ & $-25.8 \%$ & $47-49$ & Sedimento orgânico \\
\hline $\begin{array}{l}\text { Beta - 322812 } \\
\text { (JURUT1-3) }\end{array}$ & $4.700+/-30$ & $\begin{array}{c}5.420 \text { a } 5,320 \\
(5.370)\end{array}$ & $-25.6 \%$ & $57-59$ & Sedimento orgânico \\
\hline $\begin{array}{l}\text { Beta }-399323 \\
\text { (JURUT1-6) }\end{array}$ & $6.000+/-30$ & $\begin{array}{c}6.860 \text { a } 6,730 \\
(6.795)\end{array}$ & $-26.2 \%$ & $77-79$ & Sedimento orgânico \\
\hline $\begin{array}{l}\text { Beta - 322811 } \\
\text { (JURUT1-2) }\end{array}$ & $6.090+/-40$ & $\begin{array}{c}7.020 \text { a } 6,860 \\
(6.940)\end{array}$ & $-26.3 \%$ & $87-89$ & Sedimento orgânico \\
\hline $\begin{array}{l}\text { Beta }-399324 \\
\text { (JURUT1-5) }\end{array}$ & $6.350+/-30$ & $\begin{array}{c}7.275 \text { a } 7,170 \\
(7.222)\end{array}$ & $-26.1 \%$ & $117-119$ & Sedimento orgânico \\
\hline $\begin{array}{l}\text { Beta }-322810 \\
\text { (JURUT1-1) }\end{array}$ & $6.140+/-40$ & $\begin{array}{c}6.920 \text { a } 6,910 \\
(6.915)\end{array}$ & $-26.4 \%$ & $147-149$ & Sedimento orgânico \\
\hline
\end{tabular}

representaram $10 \%$ do total observado nos sedimentos (figura 3).

Descrição dos microfósseis

Fungos

Fossil Fungi insertae sedis

\section{Biporisporites}

Figura 4
Descrição: esporo unicelado, asseptado, diporado, poros situados lado a lado, forma globular ou subglobular, ornamentação psilada. Faixa de tamanho do eixo maior de 10 a $15 \mu \mathrm{m}$.

Observações e dados ecológicos: foi aventada uma possível afinidade com Trachelomonas Ehrenberg, gênero representante de Euglenophyta (Medeanic et al. 2004). No entanto, de acordo com Kalgutkar \& Jansonius (2000) espécimes deste tipo devem ser considerados esporos fúngicos, a julgar pelas suas 


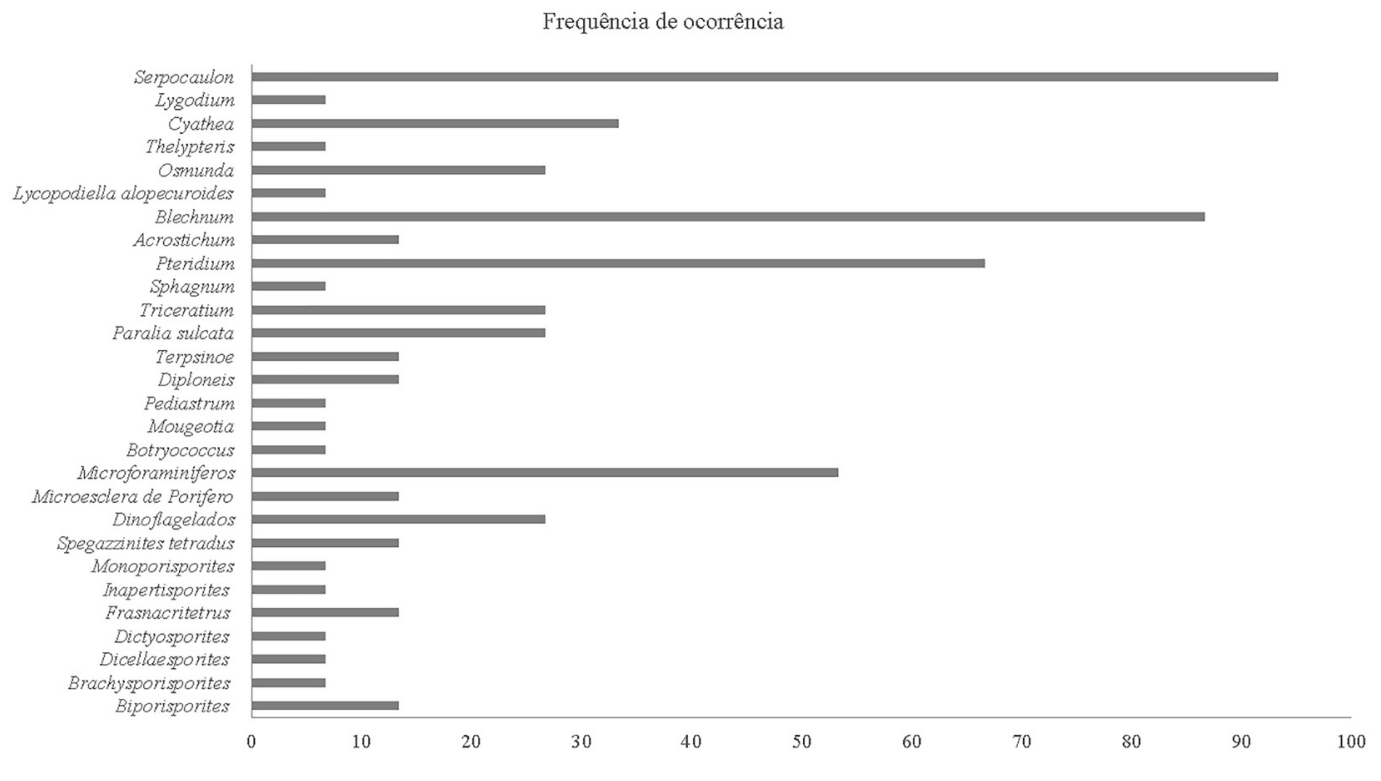

Figura 2. Frequência de ocorrência dos microfósseis não polínicos pela presença registrada nas quinze amostras do testemunho JURU T1 da Lagoa Comprida, Parque Nacional da Restinga de Jurubatiba, Rio de Janeiro, Brasil.

Figure 2. Frequency of occurrence of non-pollen microfossils by the presence recorded in the fifteen samples of JURU T1 core of the Lagoa Comprida, Jurubatiba Sandbank National Park, Rio de Janeiro, Brazil.

características estruturais. Os autores ressaltaram a necessidade de mais pesquisas para esclarecer sobre seu relacionamento à Trachelomonas. Biporisporites ocorre desde o Eoceno até o Recente (Elsik, 1981).

Ocorrência no testemunho: níveis 147-149 cm e $128-130 \mathrm{~cm}$.

\section{Brachysporisporites}

Figura 5

Descrição: esporo multicelado, disseptado, uniporado, célula distal elíptica e menor que a anterior, forma periforme, ornamentação psilada. Faixa de tamanho do eixo maior de 30 a $35 \mu \mathrm{m}$.

Observações e dados ecológicos: afinidade botânica com conídios de Brachysporium Sacc. (ascomiceto). Ocorre comumente em madeira podre e casca de árvores e arbustos de várias espécies (Ellis 1971).

Ocorrência no testemunho: nível 147-149 cm.

\section{Dicellaesporites}

Figura 6

Descrição: esporo dicelado, unisseptado, inaperturado, forma elipsoidal, com extremidades arredondadas, ornamentação psilada. Faixa de tamanho do eixo maior de 20 a $32 \mu \mathrm{m}$.
Observações e dados ecológicos: afinidade botânica com Ascomicetos, Ascosporos de Delitschia. Ocorre em águas salobras principalmente de manguezais (Elsik 1996 apud Freitas \& Carvalho 2011) e/ou como parasita sobre madeiras parcialmente submersas em água (Raja \& Shearer 2006 apud Silva et al. 2015). Ocorrência no testemunho: nível147-149cm.

\section{Dictyosporites}

Figura 7

Descrição: esporo multicelado, multiseptado, inaperturado, forma oval alongada, ornamentação psilada. Faixa de tamanho do eixo maior de 15 a $20 \mu \mathrm{m}$.

Observações e dados ecológicos: afinidade botânica com Alternaria Adelomicetos (Deuteromycotina), Arbuscula, Septosporium, Macrosporium, Stemphylium e Stigmella. Arbuscula foi registrado em folhas caídas de Eugenia sp. (Myrtaceae). Outros gêneros se relacionam a troncos de árvores decíduas e a algumas espécies de Rhamnaceae (Elsik 1996 apud Freitas \& Carvalho 2011).

Ocorrência no testemunho: nível 128-130 cm.

\section{Frasnacritetrus}

Figura 8 


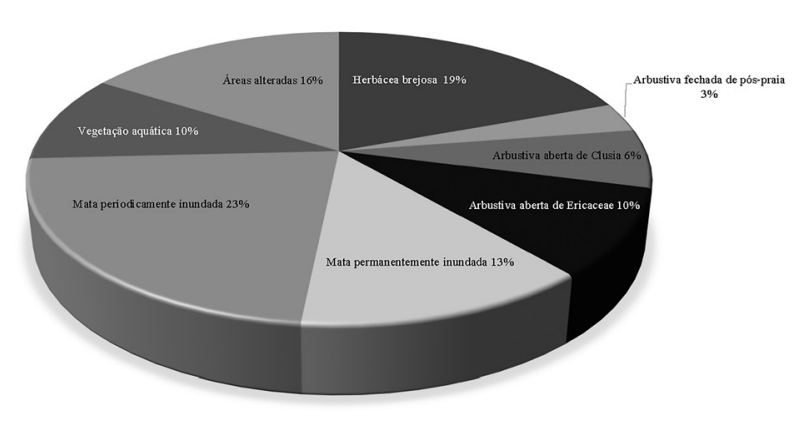

Figura 3. Frequência de ocorrência dos esporos de briófitas, licófitas e samambaias pela presença registrada nas quinze amostras do testemunho JURU T1 da Lagoa Comprida, relacionando-os às fitofisionomias onde ocorrem atualmente no Parque Nacional da Restinga de Jurubatiba.

Figure 3. Frequency of occurrence of bryophytes, lycophytes and ferns spores by the presence recorded in the fifteen samples of the JURU T1 core of Lagoa Comprida, relating them to the phytophysiognomies where they currently occur in the Jurubatiba Sandbank National Park.

Descrição: esporo multicelado, multiseptado longitudinalmente e transversalmente, composto por um corpo principal sub-retangular e três filamentos (processos) tubulares com terminações truncadas, ornamentação psilada com micropapilas na base do corpo. Faixa de tamanho do conídio (corpo mais processos) de 70 a $80 \mu \mathrm{m}$.

Observações e dados ecológicos: afinidade botânica com conídios de Tetraploa, gênero aquático de hifomiceto da família Dematiaceae que têm uma ampla distribuição geográfica, indicando clima quente e ameno e, que ocorre como saprófita nos colmos e em folhas de gramíneas, juncos e de outras plantas (Ellis 1949, Subramanian 1971, Saxena \& Sarkar 1986). Conídios de Tetraploa também são comuns na água salgada e salobra de pântanos das planícies costeiras (Medeanic et al. 2001, Limaye et al. 2007).

Ocorrência no testemunho: nível 117-119 cm.

\section{Inapertisporites}

Figura 9

Descrição: esporo unicelado, asseptado, inaperturado, forma globular ou subglobular, ornamentação psilada. Faixa de tamanho do eixo maior de 15 a $20 \mu \mathrm{m}$.

Observações e dados ecológicos: afinidade botânica com Ustilaginales (Basidiomicetos), Ustilago, Sphacelotheca Ustilaginaceae, conidiosporos de Pelicothallos villosus, Microthyriales, Geastrum- tipe, Sordaria Xilariaceae (Ascomicetos), ascosporos de Cryptocalyx clarensis e C. parvula, oosporos de Peronosporoides palmi, conídia de Cladosporites fasciculatus. Ocorrem em locais úmidos, com hábitos diversos, bastante comuns sobre esterco, madeiras e superfície de solo (Elsik 1996 apud Freitas \& Carvalho 2011, Van Geel \& Aptroot 2006 apud Silva et al. 2015).

Ocorrência no testemunho: nível 147-149 cm.

\section{Monoporisporites}

Figura 10

Descrição: esporo unicelado, asseptado, uniporado, forma esférica, ornamentação microequinada. Faixa de tamanho do eixo maior de 12 a $16 \mu \mathrm{m}$.

Observações e dados ecológicos: geralmente os esporos com espinhos tem afinidade botânica com Cortinarius, Lactarius, Lycoperdon perlatum e Russula. São cogumelos que ocorrem nos trópicos úmidos, associados com árvores e arbustos e em áreas campestres (Baseia 2005, Bazzle et al. 2015).

Ocorrência no testemunho: nível $87-89 \mathrm{~cm}$.

8. Spegazzinites tetradus (Rouse) Kalgutkar \& Janson. Figura 11

Descrição: esporo multicelado, em configuração linear tetragonal, esporos individuais circulares, ornamentação psilada. Faixa de tamanho da tétrade de 16 a $20 \mu \mathrm{m}$.

Observações e dados ecológicos: afinidade botânica com Quadrisporites Hennelly 1959 e Spegazzinites Felix 1894. De acordo com Batten (1996) atualmente considera-se que as quadrisporitas pertencem às algas verde-azuladas (Kalgutkar \& Jansonius 2000).

Ocorrência no testemunho: níveis $147-149$ cm e 128$130 \mathrm{~cm}$.

Algas Continentais

Divisão Chlorophyta

Classe Chlorophyceae

Ordem Chlorococcales

Família Hydrodictyaceae

\section{Pediastrum Meyen}

Figura 12

Descrição: indivíduos coloniais, cenóbio plano, radialmente simétrico em forma de "estrela" constituído por células periféricas e células internas morfologicamente diferentes, com parede celular lisa 

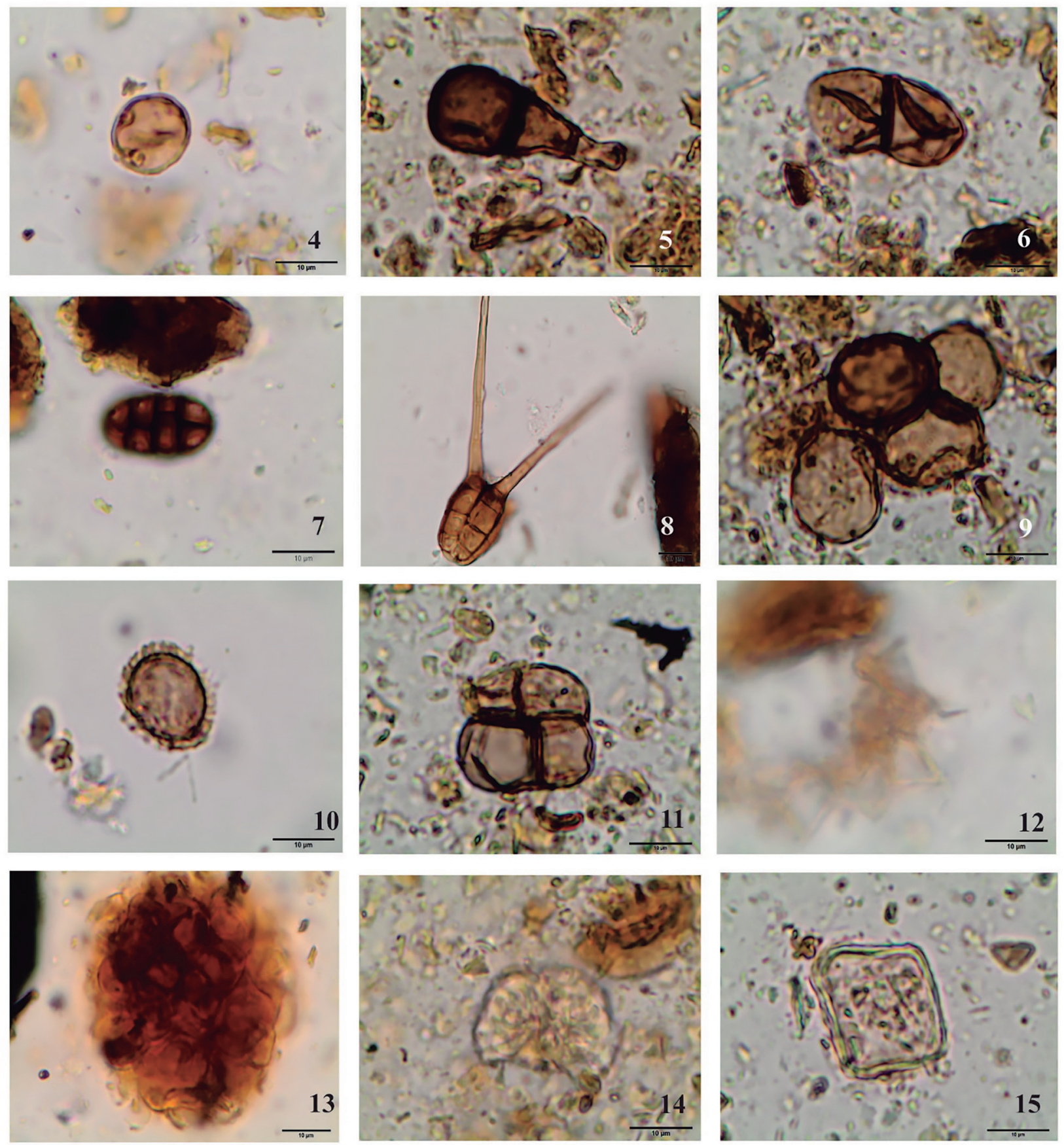

Figuras 4-15. Fotomicrografias dos palinomorfos observados nos sedimentos do testemunho JURU T1 da Lagoa Comprida, Parque Nacional da Restinga de Jurubatiba, Rio de Janeiro, Brasil. 4-11. Fossil fungi. 4. Biporisporites. 5. Brachysporisporites. 6. Dicellaesporites. 7. Dictyosporites. 8. Frasnacritetrus. 9. Inapertisporites. 10. Monoporisporites. 11. Spegazzinites tetradus. 12-15. Algas continentais Chlorococcales. 12. Pediastrum. 13-14. Botryococcus. 15. Mougeotia. Barras $=10 \mu \mathrm{m}$.

Figures 4-15. Photomicrographs of the palynomorphs observed in the sediments of the JURU T1 core samples of Lagoa Comprida, Jurubatiba Sandbank National Park, Rio de Janeiro, Brazil. 4-11. Fossil fungi. 4. Biporisporites. 5. Brachysporisporites. 6. Dicellaesporites. 7. Dictyosporites. 8. Frasnacritetrus. 9. Inapertisporites. 10. Monoporisporites. 11. Spegazzinites tetradus. 12-15. Chlorococcales continental algae. 12. Pediastrum. 13-14. Botryococcus. 15. Mougeotia. Scale bars $=10 \mu \mathrm{m}$. 
e apresentando espaços poliédricos entre elas (cenóbio clatrado). A margem livre das células periféricas apresenta um único lobo. Colônias de coloração clara, com diâmetros variando de 40 a $60 \mu \mathrm{m}$.

Observações e dados ecológicos: gênero comum no plâncton de ambientes dulcícolas ou de baixa salinidade, encontrados comumente em lagos, pântanos ou ambientes artificiais fechados. Na década de 1980 ocorria Pediastrum duplex no fitoplâncton da Lagoa Comprida (Huszar \& Esteves 1988), mas na década de 1990 foi descrito como Pediastrum simplex (Melo \& Suzuki 1998, Dias et al. 2001).

Ocorrência no testemunho: nível 117-119 cm (60,8 cenóbios $/ \mathrm{cm}^{3}$ ).

Família Trebouxiophyceae

\section{Botryococcus Kützling}

Figuras 13-14

Descrição: indivíduos coloniais, cenóbio compacto de forma irregularmente lobada a esférica, formado por elevado número de células obovóides (autósporos) densamente distribuídas na periferia de um envoltório mucilaginoso abundante. Colônias de coloração amarelo claro a castanho escuro, com diâmetros variando de 15 a $40 \mu \mathrm{m}$.

Observações e dados ecológicos: gênero cosmopolita comum no plâncton, atribuído a ambientes dulcícolas e encontrado em poças ou lagos meso- a eutróficos, de águas pouco mineralizadas. Gênero que pode ser formador de florações aquáticas em lagoas litorâneas do Estado do Rio de Janeiro. Botryococcus braunii foi citada como a alga que dominava o plâncton da Lagoa Comprida na década de 1980 (Huszar \& Esteves 1988). Já na década de 1990 Botryococcus terribilis foi identificada no fitoplâncton dessa mesma lagoa (Melo \& Suzuki 1998, Dias et al. 2001).

Ocorrência no testemunho: nível147-149 cm (126,4 cenóbios $\left./ \mathrm{cm}^{3}\right)$.

Classe Zygnematophyceae

Ordem Zygnematales

Família Zygnemataceae

\section{Mougeotia C. A. Agardh}

Figura 15

Descrição: zigósporos quadrangulares de lados estreitos e parede delgada lisa. Hialino. Diâmetro: 15 a $20 \mu \mathrm{m}$.
Observações e dados ecológicos: alga de organização filamentosa com células cilíndricas unisseriadas. Habita geralmente águas rasas de lagos e lagoas de água doce, mas pode ser encontrada também em ambientes salobres, em locais de águas rasas e estagnadas (lênticos), subaéreos lóticos, fitóticos e terrestres (solo úmido e turfa) e no fitotelma de bromélias (van Geel 1978, Hooghiemstra 1984, Dias 1997). Na Lagoa Comprida, na década de 1980 foi identificado o gênero Mougeotia sp. (Huszar \& Esteves 1988) e, na década de 1990 identificou-se Mougeotia parvula na comunidade metafítica (Dias et al. 2001).

Ocorrência no testemunho: nível 147-149 cm (252,9 zygósporos $/ \mathrm{cm}^{3}$ ).

Algas Diatomáceas

Divisão Bacillariophyta

Classe Bacillariophyceae

Ordem Naviculales

Família Diploneidaceae

12. Diploneis Ehrenb. ex Cleve

Figura 16

Descrição: alga unicelular, com padrão penado, com contorno anisobilateral em vista valvar. Valvas panduriformes, constritas na porção mediana, com ápices arredondados a cuneado-obtusos. Valvas com canais longitudinais bem desenvolvidos adjacentes à rafe, ornamentados por várias fileiras de poros. Rafe reta, filiforme. Indivíduos com 25 a $30 \mu \mathrm{m}$ de comprimento.

Observações e dados ecológicos: ocorre predominantemente em ambientes marinhos e salobros, apresentando poucas espécies de água doce (Roundet al. 1990). Huszar \& Esteves (1988) observaram representantes de Diploneis elliptica em lagoas do PARNA de Jurubatiba na década de 1980, não especificando se ocorreram na Lagoa Comprida. Essa espécie não corresponde morfologicamente ao tipo aqui observado, pois a dos autores citados não apresenta constrição mediana. Diploneis não foi observado nos estudos de Dias et al. (2001) e Alvesde-Souza et al. (2006) para a década de 1990 na Lagoa Comprida.

Ocorrência no testemunho: níveis $137-139 \mathrm{~cm}(1.206$ frústulas $\left./ \mathrm{cm}^{3}\right)$ e em 147-149 cm (316,1 frústulas $\left./ \mathrm{cm}^{3}\right)$.

Classe Coscinodiscophyceae

Ordem Paraliales

Família Paraliaceae 



Figuras 16-27. Fotomicrografias dos palinomorfos observados nos sedimentos do testemunho JURU T1 da Lagoa Comprida, Parque Nacional da Restinga de Jurubatiba, Rio de Janeiro, Brasil. 16-20. Diatomáceas. 16. Diploneis. 17-18. Paralia sulcata. 19. Triceratium. 20. Terpsinoё. 21-24. Dinoflagelados. 21-23. Operculodinium centrocarpum. 24. Spiniferites. 25. Microforaminífero. 26-27. Microsclera de porífero. Barras $=10 \mu \mathrm{m}$.

Figures 16-27. Photomicrographs of the palynomorphs observed in the sediments of the JURU T1 core samples of Lagoa Comprida, Jurubatiba Sandbank National Park, Rio de Janeiro, Brazil. 16-20. Diatoms. 16. Diploneis. 17-18. Paralia sulcata. 19. Triceratium. 20. Terpsinö̈. 21-24. Dinoflagellates. 21-23. Operculodinium centrocarpum. 24. Spiniferites. 25. Microforaminifer. 26-27. Spicule of porifera. Scale bars $=10 \mu \mathrm{m}$. 


\section{Paralia sulcata (Ehrenberg) Cleve}

Figuras 17-18

Descrição: alga unicelular, com padrão cêntrico, com contorno circular em vista valvar. Valvas robustas e fortemente silicificadas. Esqueleto extracelular opalino de aparência vítrea. Diâmetro da face valvar de 20 a $30 \mu \mathrm{m}$.

Observações e dados ecológicos: diatomácea pleio-eurihalina, tolerando salinidades de 5-35us. De natureza ticopelágica, nerítica e bentônica de ambientes marinhos costeiros, ocasionalmente no plâncton devido a ventos e marés que podem transportá-la. Pode também ser epífita de macroalgas. Indicadora de situação de ressurgência costeira resultando em alta produção primária (McQuoida \& Nordberg 2003, AlgaeBase 2018). Sua presença, crescimento e abundância é limitada pela profundidade de penetração da luz na coluna de água e do tipo de substrato e não tanto pela salinidade, preferindo águas com pouca transparência e sedimentos finos a areias (Round et al. 1990, Zong 1997). Não foram observados representantes desse gênero na Lagoa Comprida nos estudos de Huszar \& Esteves (1988), Dias et al. (2001) e Alves-de-Souza et al. (2006) para as décadas de 1980 e 1990.

Ocorrência no testemunho: níveis $117-119 \mathrm{~cm}(1.762,2$ frústulas $\left./ \mathrm{cm}^{3}\right), 128-130 \mathrm{~cm}\left(46.725,1\right.$ frústulas $\left./ \mathrm{cm}^{3}\right)$, $137-139 \mathrm{~cm}\left(121.349,9\right.$ frústulas $\left./ \mathrm{cm}^{3}\right)$ e em 147-149 $\mathrm{cm}\left(16.056,8\right.$ frústulas $\left./ \mathrm{cm}^{3}\right)$.

\section{Ordem Triceratiales \\ Família Triceratiaceae}

\section{Triceratium Ehrenberg}

Figura 19

Descrição: alga unicelular, células de vida livre ou agrupadas, triangular em vista valvar e oblonga estreita em vista pleural, com elevações nos cantos e uma ligeira convexidade central. Indivíduos de 40 a $80 \mu \mathrm{m}$ de comprimento.

Observações e dados ecológicos: marinha, costeira (Guiry \& Guiry 2018). Não foram observados representantes desse gênero na Lagoa Comprida em Huszar \& Esteves (1988), Dias et al. (2001) e Alvesde-Souza et al. (2006) para as décadas de 1980 e 1990. Ocorrência no testemunho: níveis 117-119 cm (546,9 frústulas $\left./ \mathrm{cm}^{3}\right), 128-130 \mathrm{~cm}\left(1.690,7\right.$ frústulas $\left./ \mathrm{cm}^{3}\right)$, $137-139 \mathrm{~cm}$ (2.261,2 frústulas $\left./ \mathrm{cm}^{3}\right)$ e em $147-149 \mathrm{~cm}$ $\left(632,2\right.$ frústulas $\left./ \mathrm{cm}^{3}\right)$.
Classe Mediophyceae

Ordem Anaulales

Família Anaulaceae

\section{Terpsinö̈ Ehrenberg}

Figura 20

Descrição: alga unicelular, tabular, entalhadas, com pseudosepta conspícua em vista pleural, marcadamente alongada e ondulada na vista valvar. Indivíduos de 40 a $50 \mu \mathrm{m}$ de comprimento.

Observações e dados ecológicos: para Guiry \& Guiry (2018) e Round et al. (1990) Terpsinoë é um gênero com distribuição ecológica muito precisa em regiões tropicais, formando colônias epifíticas ou epilíticas em“zig-zag”, preferindo ambientes eurialínicos de águas salobras ou doce. Frequentemente é observado sobre rochas úmidas. Não foram observados representantes desse gênero na Lagoa Comprida em Huszar \& Esteves (1988), Dias et al. (2001) e Alvesde-Souza et al. (2006) para as décadas de 1980 e 1990.

Ocorrência no testemunho: níveis 137-139 cm (75,4 frústulas $\left./ \mathrm{cm}^{3}\right)$ e 147-149 $\mathrm{cm}\left(63,2\right.$ frústulas $\left./ \mathrm{cm}^{3}\right)$.

Dinoflagelados

Reino Chromista

Divisão Miozoa

Classe Dinophyceae

Ordem Dynophyceae ordo insertae sedis Família Dinophyceae insertae sedis

\section{Operculodinium centrocarpum (Deflandre \&} Cookson) Wall

Figuras 21-23

Descrição: cisto corado (altura das projeções $>30 \%$ do diâmetro do corpo central), com corpo central esférico e ornamentado com 20 a 40 projeções/ processos simples e delgados que apresentam base cônica, com veios finos e terminações capitulares ou bífidas. Comprimento dos processos pode variar de um quinto a um quarto do diâmetro do corpo do cisto. Corpo do cisto de cerca de 35 a $45 \mu \mathrm{m}$ de diâmetro.

Observações e dados ecológicos: é uma espécie cosmopolita associada às áreas de transição da zona costeira e o oceano. É altamente tolerante a mudanças rápidas e/ou instabilidade ambiental, mas sua maior abundância relativa ocorre em ambientes com temperaturas baixas e alta salinidade. Pode ser indicadora de sistemas de ressurgência costeira. Apresenta moderada resistência à exposição ao oxigênio. Geralmente o enquistamento ocorre depois 
de períodos de crescimento exponencial, como por exemplo, depois dos "blooms" (Dale 1996, Marret \& Zonneveld 2003, Santos et al. 2017).

Ocorrência no testemunho: níveis $66-68 \mathrm{~cm}, 77-79$ $\mathrm{cm}, 107-109 \mathrm{~cm}, 117-119 \mathrm{~cm}$.

\section{Spiniferites G.A. Mantell}

Figura 24

Descrição: cisto corado (altura das projeções $>30 \%$ do diâmetro do corpo central), com corpo central esférico e ornamentado com 10 a 20 projeções/processos simples e delgados que apresentam base cônica, com veios finos e terminações bífidas. Comprimento dos processos pode variar de um quinto a um quarto do diâmetro do corpo do cisto. Corpo do cisto com cerca de 30 a $35 \mu \mathrm{m}$ de diâmetro.

Observações e dados ecológicos: espécies do gênero tem uma ampla distribuição na Província Nerítica, com maior abundância ocorrendo em ambientes oligotróficos (Souza 2012).

Ocorrência no testemunho: nível $66-68 \mathrm{~cm}$.

Microforaminíferos

Reino Chromista

Divisão Foraminifera

Classe Globothalamea

Ordem Rotaliida

Familia Rotalioidea

\section{Microforaminífero Tipo 1}

Figura 25

Descrição: teca com testas internas quitinosas, com câmaras hialinas em formato espiralado (planispiral, tipo II de Stancliffe 1989) composta por 6 a 8 câmaras lisas. Diâmetro total da teca variando de 35 a $45 \mu \mathrm{m}$.

Observações e dados ecológicos: são predominantemente marinhos, bentônicos ou planctônicos, ocorrendo em mar aberto ou em habitats de transição como lagunas, estuários, deltas ou manguezais, sendo as maiores frequências encontradas em ambiente nerítico raso (Pedrão \& Carvalho 2002, SalgadoLabouriau 2007). Os foraminíferos planctônicos são exclusivamente marinhos, enquanto que os bentônicos habitam desde a região entre-marés até a abissal (Duleba et al. 2005).

Ocorrência no testemunho: níveis $08-10 \mathrm{~cm}$ $\left(922,2\right.$ miocroforaminíferos $\left./ \mathrm{cm}^{3}\right), 19-20 \mathrm{~cm}$ $\left(388,1\right.$ miocroforaminíferos $\left./ \mathrm{cm}^{3}\right), 47-49 \mathrm{~cm}$ $\left(304,4\right.$ microforaminíferos $\left./ \mathrm{cm}^{3}\right), 57-59 \mathrm{~cm}$
(156,8 microforaminíferos $\left./ \mathrm{cm}^{3}\right), 66-68 \mathrm{~cm}$ (74 microforaminíferos/ $\left.\mathrm{cm}^{3}\right), 97-99 \mathrm{~cm}(42,8$ microforaminíferos $\left./ \mathrm{cm}^{3}\right), 117-119 \mathrm{~cm}(303,8$ microforaminíferos $\left./ \mathrm{cm}^{3}\right)$ e em 147-149 cm (316,1 microforaminíferos $/ \mathrm{cm}^{3}$ ).

Microfóssil de porífero

Reino Animalia

Divisão Porifera

\section{Microsclera de porífero Tipo 1}

Figuras 26-27

Descrição: unidade do esqueleto espicular de um organismo. Microsclera silicosa do tipo hexáster (espículas de tamanho reduzido e com a superfície recoberta por espinhos) (Laubenfels 1955). Microsclera com cerca de $40 \mu \mathrm{m}$ de diâmetro.

Observações e dados ecológicos: a espícula se desagrega do invertebrado (esponja) estacionalmente de maneira que a espongina é rapidamente decomposta, liberando as espículas silicosas. A morfologia da microesclera de porífero sugere que se trate de uma espécie de água doce (Dr. Mauro Parolin e MSc Karen Silva, comunicação pessoal). A literatura especializada assinala sobre a suscetibilidade das esponjas de água doce às mínimas alterações ambientais e a presença dessa fauna aponta para uma excelente qualidade da água, já que são filtradores. Dada a constituição de sílica amorfa dessas espículas, apresentam tendência para preservação como elemento esparso junto ao sedimento, sendo observadas em depósitos lacustres do Quaternário (Silva et al. 2009, Volkmer-Ribeiro \& Parolin 2010).

Ocorrência no testemunho: níveis $87-89 \mathrm{~cm}$ e $107-$ $109 \mathrm{~cm}$.

\section{Briófitas \\ Reino Plantae \\ Divisão Bryophyta \\ Subdivisão Musci \\ Classe Sphagnopsida \\ Ordem Sphagnales \\ Família Sphagnaceae}

\section{Sphagnum L.}

Figura 28

Descrição: esporos triletes de tamanho pequeno, heteropolares, tetraédrico-globosos, braços da lesão com bifurcações nas extremidades, exósporio psilado e espessamento trilobado no pólo distal, irregularmente dispostos. Esporos com 22 a $24 \mu \mathrm{m}$ de eixo equatorial. 

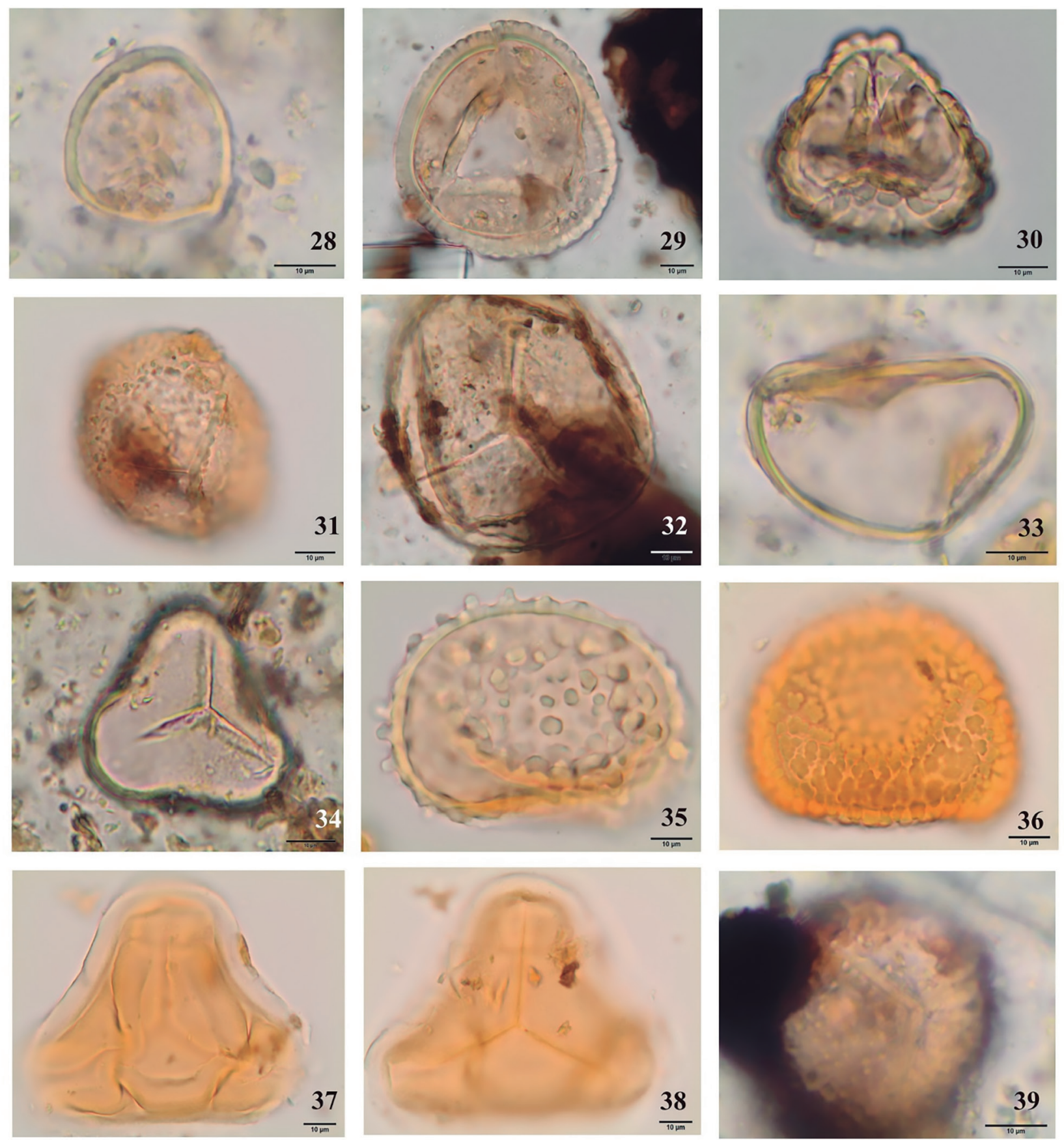

Figuras 28-39. Fotomicrografias dos palinomorfos observados nos sedimentos do testemunho JURU T1 da Lagoa Comprida, Parque Nacional da Restinga de Jurubatiba, Rio de Janeiro, Brasil. 28. Briófita, Sphagnum. 29. Licófita, Lycopodiella alopecuroides. 30-39. Samambaias. 30. Cyathea. 31-32. Osmunda. 33. Blechnum. 34. Pteridium. 35. Serpocaulon. 36. Thelypteris. 37-38. Lygodium. 39. Acrostichum. Barras $=10 \mu \mathrm{m}$.

Figures 28-39. Photomicrographs of the palynomorphs observed in the sediments of the JURU T1 core samples of Lagoa Comprida, Jurubatiba Sandbank National Park, Rio de Janeiro, Brazil. 28. Bryophyte, Sphagnum. 29. Lycophyte, Lycopodiella alopecuroides. $30-39$. Ferns. 30. Cyathea. 31-32. Osmunda. 33. Blechnum. 34. Pteridium. 35. Serpocaulon. 36. Thelypteris. 37-38. Lygodium. 39. Acrostichum. Scale bars $=10 \mu \mathrm{m}$. 
Observações e dados ecológicos: segundo Imbassahy et al. (2009) os tufos longos de quatro espécies terrícolas de Sphagnum (Sphagnum cuspidatum Ehrh. ex Hoffm., S. palustre L., S. perichaetiale Hampe e $S$. sparsum Hampe) que ocorrem no PARNA de Jurubatiba só foram observados em áreas bastante úmidas, como brejos e alagados, ou áreas sombreadas, como o interior de moitas ou da mata.

Ocorrência no testemunho: nível 137-139 cm (150,7 esporos $/ \mathrm{cm}^{3}$ ).

Licófitas

Reino Plantae

Divisão Lycopodiophyta

Classe Lycopodiopsida

Ordem Lycopodiales

Familia Lycopodiaceae

21. Lycopodiella alopecuroides (L.) Cranfill.

Figura 29

Descrição: esporos triletes de tamanho grande, heteropolares, esferoidais, com borda equatorial proeminente, braços da lesão aproximadamente com $2 / 3$ do raio, exósporo rugulado-reticulado mais proeminente no pólo distal, com tubérculos (projeções curtas, arredondadas) entre os braços da lesão. Tubérculos pequenos. Esporos com 78 a $85 \mu \mathrm{m}$ de eixo equatorial.

Observações e dados ecológicos: no PARNA de Jurubatiba ocorre Lycopodiella alopecuroides var. integerrima (Spring) B. Ollgaard \& P.G. Windisch que é uma erva terrícola da formação herbácea brejosa, associada a Drosera intermedia Hayne s.1., Lindsaea stricta var. stricta e Sphagnum sp. (Santos \& Sylvestre 2001). Essa espécie ocorreu na Lagoa Comprida como planta aquática anfíbia no levantamento florístico de Bove \& Paz (2009).

Ocorrência no testemunho: nível 117-119 cm (1,26 esporos $/ \mathrm{cm}^{3}$ ).

Samambaias

Reino Plantae

Divisão Monilophyta

Classe Polypodiopsida

Ordem Cyatheales

Família Cyatheaceae

\section{Cyathea J.Sm.}

Figura 30

Descrição: esporos triletes de tamanho médio, heteropolares, tetraédrico-globosos, braços da lesão com aproximadamente $3 / 4$ do raio, exosporo com verrugas, verrugas orientadas paralelamente em torno dos braços da lesão. Esporos com 36 a $40 \mu \mathrm{m}$ de eixo equatorial.

Observações e dados ecológicos: Santos \& Sylvestre (2001) apontaram duas espécies para o PARNA de Jurubatiba, Cyathea delgadii Sternb. e C. microdonta (Desv.) Domin. A primeira é arborescente e ocorre na mata periodicamente inundada, sendo incomum na região. Já Cyathea microdonta apresenta mais coletas registradas no PARNA de Jurubatiba e ocorre somente como herbácea terrícola na mata periodicamente inundada, apesar de também possuir hábito arborescente em outros locais.

Ocorrência no testemunho: níveis 47-49 cm $(76,1$ esporos $\left./ \mathrm{cm}^{3}\right), 57-59 \mathrm{~cm}\left(156,8\right.$ esporos $\left./ \mathrm{cm}^{3}\right), 66-68$ $\mathrm{cm}\left(147,9\right.$ esporos $\left./ \mathrm{cm}^{3}\right), 77-79 \mathrm{~cm}\left(74,7\right.$ esporos $\left./ \mathrm{cm}^{3}\right)$ e em $87-89 \mathrm{~cm}\left(76,9\right.$ esporos $\left./ \mathrm{cm}^{3}\right)$.

\section{Ordem Osmundales \\ Familia Osmundaceae}

\section{Osmunda L.}

Figuras 31-32

Descrição: esporos triletes de tamanho grande, heteropolares, esferoidais, braços da lesão com aproximadamente $3 / 4$ do raio, exosporo com tubérculos, perisporo com espículos acima dos tubérculos. Esporos com 52 a $72 \mu \mathrm{m}$ de eixo equatorial. Observações e dados ecológicos: é uma erva terrícola que pode ocorrer em margens de lagos e pode invadir áreas encharcadas (Flora do Brasil 2020 2018). No PARNA de Jurubatiba não foram coletadas plantas desse gênero. Em outras áreas de restinga do Rio de Janeiro foram observadas as espécies Osmunda cinnamomea L. e Osmunda regalis L. (Santos \& Araújo 2007).

Ocorrência no testemunho: níveis $08-10 \mathrm{~cm}(153,7$ esporos $\left./ \mathrm{cm}^{3}\right), 19-20 \mathrm{~cm}\left(310,4\right.$ esporos $\left./ \mathrm{cm}^{3}\right), 36-38$ $\mathrm{cm}\left(77,6\right.$ esporos/ $\left.\mathrm{cm}^{3}\right)$ e $137-139 \mathrm{~cm}(226,1$ esporos/ $\left.\mathrm{cm}^{3}\right)$.

$$
\begin{aligned}
& \text { Ordem Polypodiales } \\
& \text { Família Blechnaceae }
\end{aligned}
$$

\section{Blechnum L.}

\section{Figura 33}

Descrição: esporos monoletes de tamanho médio a grande, heteropolares, elipsoidais, lesão com aproximadamente $3 / 4$ do raio, exosporo psilado. 
Esporos com 40 a $55 \mu \mathrm{m}$ de eixo equatorial maior. Observações e dados ecológicos: segundo Santos \& Sylvestre (2001) e Araujo et al. (1998) no PARNA de Jurubatiba ocorre Blechnum serrulatum Rich. como erva terrícola na mata periodicamente inundada, assim como na herbácea brejosa, formação de Ericaceae e em áreas alteradas. Encontra-se frequentemente associada com Pteridium aquilinum var. arachnoideum e Thelypteris interrupta (às margens da mata periodicamente inundada e nas estradas) e pode comportar-se como espécie invasora. De acordo com Bove \& Paz (2009) B. serrulatum ocorre como planta aquática anfíbia na Lagoa de Carapebus, Lagoa Amarra-boi e na Lagoa de Jurubatiba, mas não foi observada na Lagoa Comprida.

Ocorrência no testemunho: níveis 08- $10 \mathrm{~cm}(76,9$ esporos $\left./ \mathrm{cm}^{3}\right), 19-20 \mathrm{~cm}\left(77,6\right.$ esporos $\left./ \mathrm{cm}^{3}\right), 36-38$ $\mathrm{cm}\left(77,6\right.$ esporos $\left./ \mathrm{cm}^{3}\right), 47-49 \mathrm{~cm}$ (76,1 esporos/ $\left.\mathrm{cm}^{3}\right), 57-59 \mathrm{~cm}\left(78,4\right.$ esporos $\left./ \mathrm{cm}^{3}\right), 66-68 \mathrm{~cm}(147,9$ esporos $\left./ \mathrm{cm}^{3}\right), 87-89 \mathrm{~cm}\left(230,6\right.$ esporos/ $\left.\mathrm{cm}^{3}\right), 97-99$ $\mathrm{cm}\left(85,7\right.$ esporos $\left./ \mathrm{cm}^{3}\right), 107-109 \mathrm{~cm}$ (51,6 esporos/ $\left.\mathrm{cm}^{3}\right), 117-119 \mathrm{~cm}\left(243,1\right.$ esporos $\left./ \mathrm{cm}^{3}\right), 128-130 \mathrm{~cm}$ (76,9 esporos $\left./ \mathrm{cm}^{3}\right), 137-139 \mathrm{~cm}\left(452,2\right.$ esporos $\left./ \mathrm{cm}^{3}\right)$ e em 147-149 cm $\left(189,6\right.$ esporos $\left./ \mathrm{cm}^{3}\right)$.

Família Dennstaedtiaceae

25. Pteridium Gled. ex Scop.

Figura 34

Descrição: esporos triletes de tamanho médio, heteropolares, tetraédrico-globosos, braços da lesão com aproximadamente $2 / 3$ do raio, exósporo levemente ondulado. Esporos com 35 a $42 \mu \mathrm{m}$ de eixo equatorial.

Observações e dados ecológicos: no PARNA de Jurubatiba ocorre a espécie herbácea terrícola Pteridium aquilinium var. arachnoideum (Kaulf.) Brade nas formações de Clusia e Ericaceae, nas bordas da mata periodicamente inundada e em áreas alteradas. É espécie invasora juntamente com Blechnum serrulatum e dominante em área de vegetação alterada (Santos \& Sylvestre 2001).

Ocorrência no testemunho: níveis 08-10 cm $(153,7$ esporos $\left./ \mathrm{cm}^{3}\right), 19-20 \mathrm{~cm}\left(77,6\right.$ esporos/ $\left.\mathrm{cm}^{3}\right), 27-29$ $\mathrm{cm}\left(405,5\right.$ esporos $\left./ \mathrm{cm}^{3}\right), 36-38 \mathrm{~cm}(77,6$ esporos/ $\left.\mathrm{cm}^{3}\right), 66-68 \mathrm{~cm}\left(147,9\right.$ esporos $\left./ \mathrm{cm}^{3}\right), 77-79 \mathrm{~cm}(149,3$ esporos $\left./ \mathrm{cm}^{3}\right), 87-89 \mathrm{~cm}\left(153,7\right.$ esporos $\left./ \mathrm{cm}^{3}\right), 107-109$ $\mathrm{cm}\left(51,6\right.$ esporos $\left./ \mathrm{cm}^{3}\right), 137-139 \mathrm{~cm}$ (226,1 esporos/ $\left.\mathrm{cm}^{3}\right)$ e em 147-149 cm $\left(316,1\right.$ esporos/ $\left.\mathrm{cm}^{3}\right)$.

Família Polypodiaceae
26. Serpocaulon A.R. Sm.

Figura 35

Descrição: esporos monoletes de tamanho médio a grande, heteropolares, elipsoidais, lesão com aproximadamente $3 / 4$ do raio, exosporo com verrugas protuberantes. Esporos com 42-55 $\mu \mathrm{m}$ de eixo equatorial maior.

Observações e dados ecológicos: Serpocaulon foi segregado de Polypodium L.com cerca de 42 espécies, como uma linhagem monofilética de espécies exclusivamente neotropicais (Smith et al. 2006). Santos \& Sylvestre (2001) indicaram três espécies de Polypodium no PARNA de Jurubatiba, $P$. loriceum L., P. polypodioides var. minus (Fée) Weath. e $P$. triseriale $\mathrm{Sw}$. A primeira é erva terrícola na mata periodicamente inundada e pouco frequente na área de estudo, a segunda é erva epífita na formação arbustiva fechada de pós-praia e, a terceira é erva terrícola muito frequente nas formações arbustiva aberta de Clusia, arbustiva aberta de Ericaceae, mata periodicamente inundada e nas margens das lagoas.

Ocorrência no testemunho: níveis 19-20 cm (4 esporos $\left./ \mathrm{cm}^{3}\right), 27-29 \mathrm{~cm}\left(5,26\right.$ esporos $\left./ \mathrm{cm}^{3}\right), 36-38 \mathrm{~cm}$ $\left(11,11\right.$ esporos $\left./ \mathrm{cm}^{3}\right), 47-49 \mathrm{~cm}\left(2,5\right.$ esporos $\left./ \mathrm{cm}^{3}\right)$, $57-59 \mathrm{~cm}\left(11,54\right.$ esporos/ $\left.\mathrm{cm}^{3}\right), 66-68 \mathrm{~cm}$ (5 esporos/ $\left.\mathrm{cm}^{3}\right), 77-79 \mathrm{~cm}\left(13,23\right.$ esporos $\left./ \mathrm{cm}^{3}\right), 87-89 \mathrm{~cm}$ $\left(9,76\right.$ esporos $\left./ \mathrm{cm}^{3}\right), 97-99 \mathrm{~cm}\left(9,91\right.$ esporos $\left./ \mathrm{cm}^{3}\right)$, $107-109 \mathrm{~cm}(7,14$ esporos/cm 3$), 117-119 \mathrm{~cm}(6,33$ esporos $\left./ \mathrm{cm}^{3}\right), 128-130 \mathrm{~cm}\left(3,70\right.$ esporos $\left./ \mathrm{cm}^{3}\right)$, $137-139 \mathrm{~cm}\left(3,92\right.$ esporos $\left./ \mathrm{cm}^{3}\right)$ e $147-149 \mathrm{~cm}(4,43$ esporos $\left./ \mathrm{cm}^{3}\right)$.

\section{Família Thelypteridaceae}

\section{Thelypteris Schmidel}

Figura 36

Descrição: esporos monoletes de tamanho médio a grande, heteropolares, elipsoidais, lesão com aproximadamente $2 / 3$ a $3 / 4$ do raio, exósporo com gemas (bulas mais largas que altas e contraídas na base). Esporos com 45 a $56 \mu \mathrm{m}$ de eixo equatorial. Observações e dados ecológicos: no PARNA de Jurubatiba ocorrem três espécies, Thelypteris interrupta (Willd.) K. Iwats., T. longifolia (Desv.) R.M. Tryon e T. serrata (Cav.) Alston. São ervas terrícolas da mata periodicamente inundada e mata permanentemente inundada. Em áreas alteradas T. interrupta ocorre associada principalmente a Blechnum serrulatum. 
Ocorrência no testemunho: nível 27-29 cm (67,6 esporos $/ \mathrm{cm}^{3}$ ).

\section{Ordem Schizaeales \\ Família Lygodiaceae}

\section{Lygodium Sw.}

Figuras 37-38

Descrição: esporos triletes de tamanho grande a muito grande, heteropolares, tetraédrico-globosos, braços da lesão com aproximadamente $3 / 4$ a igual comprimento do raio, exósporo psilado formando cristas. Esporos com 73 a $85 \mu \mathrm{m}$ de eixo equatorial.

Observações e dados ecológicos: Santos \& Sylvestre (2001) apontaram a espécie herbácea terrícola escandente Lygodium volubile Sw. como a única do gênero que ocorre no PARNA de Jurubatiba, na mata periodicamente inundada, mata permanentemente inundada e em áreas alteradas.

Ocorrência no testemunho: nível $08-10 \mathrm{~cm}(2,38$ esporos $/ \mathrm{cm}^{3}$ ).

\section{Classe Pteridopsida Ordem Pteridales Família Pteridaceae}

\section{Acrostichum L.}

Figura 39

Descrição: esporos triletes de tamanho médio, heteropolares, tetraédrico-globosos a globosos, lesão com aproximadamente $1 / 2$ do raio, exósporo psilado com rugas, perisporo apresentando papilas (elevações cilíndricas) curtas. Esporos com 28 a $32 \mu \mathrm{m}$ de eixo equatorial.

Observações e dados ecológicos: no PARNA de Jurubatiba ocorre Acrostichum danaeifolium Langsd. \& Fisch. que é uma erva terrícola da mata permanentemente inundada, assim como da formação herbácea brejosa e de áreas alteradas (alagados dominados por Typha domingensis) (Santos \& Sylvestre 2001). Nas lagoas do PARNA de Jurubatiba, Acrostichum danaeifolium ocorreu como planta aquática anfíbia na Lagoa Preta, Lagoa do Pires e Lagoa de Jurubatiba, mas não foi observada na Lagoa Comprida (Bove \& Paz 2009).

Ocorrência no testemunho: níveis $117-119 \mathrm{~cm}(60,8$ esporos $\left./ \mathrm{cm}^{3}\right)$ e $137-139 \mathrm{~cm}\left(603\right.$ esporos $\left./ \mathrm{cm}^{3}\right)$.

\section{Discussão}

$\mathrm{Na}$ atualidade a Lagoa Comprida se configura como um sistema de águas doces a raramente oligohalinas (Dias et al. 2001, Enrich-Prast et al. 2004, Caliman et al. 2010), mas na base do testemunho a água era provavelmente mais salobra, pelo menos na barra da lagoa, segundo a deposição de cistos de dinoflagelados e microforaminíferos, além de diatomáceas marinhas ou de água salobra não observadas nos levantamentos ficológicos atuais de Huszar \& Esteves (1988), Melo \& Suzuki (1998), Dias et al. (2001) e Alves-de-Souza et al. (2006). Os elementos marinhos ou de águas salobras que predominaram na base do testemunho da Lagoa Comprida desapareceram do registro a cerca de 25 anos após o início de sua sedimentação, o que pode indicar interrupção da influência marinha na lagoa.

Atualmente a Lagoa Comprida apresenta uma rica comunidade ficológica, apesar de ser uma das menores entre as 18 lagunas do Parque Nacional da Restinga de Jurubatiba (Huszar \& Esteves 1988, Dias et al. 2001, Alves-de-Souza et al. 2006). $\mathrm{Na}$ época presente foram identificados 61 táxons específicos e infra-específicos na comunidade ficológica planctônica, metafítica e perifítica da Lagoa Comprida, sendo 47 planctônicos (Dias et al. 2001). Entre estes táxons os que podem corresponder aos microfósseis observados no sedimento do testemunho são Pediastrum simplex e Botryococcus terribilis da comunidade plânctonica e Mougeotia parvula da metafítica. A alta produtividade dessas algas se dá por reprodução assexual, que costuma ocorrer sob condições favoráveis, ou reprodução sexual, que ocorre geralmente em condições menos favoráveis (Brenner \& Foster 1994, Jansonius \& Mcgregor 1996). Estas algas só foram observadas em dois níveis da base do testemunho e com baixa concentração. A baixa riqueza na assembleia ficológica fóssil pode ser explicada pela ausência de esporopolenina nas paredes celulares da maioria dos táxons e, conforme salientado por Traverse (2007), devido aos processos tafonômicos e mudanças ambientais ao longo do tempo.

Nos nossos resultados a densidade das espículas de esponjas dulcícolas nas lâminas de microscopia foi rara, ocorrendo apenas em dois níveis do testemunho, correspondendo ao período entre $6.090+/-40$ anos AP (6.940 cal anos AP) e $6.350+/-30$ anos AP (7.222 cal anos AP), quando não foram mais observados microfósseis indicadores de influência marinha.

Com relação aos componentes terrícolas, várias formas foram observadas em grande parte do período analisado, como esporos de fungos, briófitas, licófitas 
e samambaias, que confirmaram a existência de ambientes bastante úmidos no entorno da Lagoa Comprida, periodicamente ou permanentemente inundados com água doce, como brejos e alagados.

Fungos, obrigatoriamente heterotróficos, estão associados a determinadas plantas ou animais e são considerados como "in situ" em sedimentos superficiais de solo, servindo como material complementar na caracterização do ambiente terrestre e sugerindo aporte terrígeno para um lago (Kalgutkar \& Jansonius 2000, Van Geel 2001, Medeanic et al. 2004). Os esporos de fungos aqui identificados, sobretudo encontrados na parte inferior do depósito, apresentaram características semelhantes às espécies atuais de Ascomicetos, Adelomicetos, Basidiomicetos e Hifomicetos, ocorrendo em locais muito úmidos da superfície de solos ou em aguas salobras e, como saprófitos em madeira ou folhas caídas.

Quanto às licófitas e samambaias, na atualidade do PARNA de Jurubatiba foram identificadas 12 famílias, 21 gêneros e 31 espécies, sendo Polypodiaceae e Pteridaceae as famílias com maior número de gêneros (Santos \& Sylvestre 2001). No levantamento florístico atual realizado por Bove \& Paz (2009) somente Lycopodiella alopecuroides foi identificada como planta aquática anfíbia na Lagoa Comprida, apesar de Acrostichum danaeifolium e Blechnum serrulatum ocorrerem no espelho d'água de outras lagoas do PARNA de Jurubatiba. No testemunho da Lagoa Comprida somente foram observados os esporos de Acrostichum, Blechnum, Lycopodiella alopecuroides, Lygodium, Pteridium, Serpocaulon e Thelypteris, representando apenas 33\% dos gêneros amostrados atualmente no parque. Os esporos de briófitas, licófitas e samambaias observados no testemunho sugerem aporte terrígeno, principalmente de áreas úmidas adjacentes à Lagoa Comprida e relacionadas a Fitofisionomias da "Mata Periodicamente Inundada", "Mata Permanentemente Inundada" e "Herbácea brejosa". Estima-se que a produção de esporos de uma única fronde de samambaia varie de $750.000 \mathrm{a}$ 750.000 .000 de esporos, dependendo da espécie (Page 1979). No entanto, na maioria dos habitats os esporos são liberados por um tempo limitado e dispersos com uma baixa taxa de vicariância, depositando-se diferencialmente conforme a batimetria e outros fatores físicos em um lago devido aos seus tamanhos, o que pode explicar, nos sedimentos analisados, a baixa concentração e riqueza de vários gêneros de esporos. No entanto, em certas espécies os esporos podem ser liberados ao longo de muitos meses por ano, causando super-representação nos sedimentos (Luz
2012, Luz 2013, Coelho et al. 2017). Os esporos de Serpocaulon apresentaram as maiores concentrações nos sedimentos, seguidos de Blechnum e Pteridium, figurando como os gêneros de samambaias com maior número de habitats e distribuição geográfica na atualidade, o que pode explicar suas altas frequências de ocorrência nas amostras.

Conclui-se que as assembleias de microfósseis não polínicos depositadas na Lagoa Comprida sugerem mudanças ambientais ocorridas durante o Holoceno médio, com indicação de deposição de sedimentos sob influência marinha no início do período analisado, com posterior desaparecimento e restabelecimento das condições dulcícolas.

\section{Agradecimentos}

Ao Dr Felipe Mesquita de Vasconcellos e Dr $^{\mathrm{a}}$ Claudia Gutterres Vilela pela coleta do testemunho. Ao Dr Luciano Mauricio Esteves e Dra Carolina Brandão Coelho pelo auxílio nas identificações dos esporos de samambaias e licófitas. Ao Dr. Carlos Eduardo de Mattos Bicudo, Dr ${ }^{\mathrm{a}}$ Denise de Campos Bicudo e Dr ${ }^{\mathrm{a}}$ Gabrielle Joanne Medeiros Araújo pelas identificações das diatomáceas. A Dr ${ }^{\mathrm{a}}$ Cristiane Degobbi Coelho e sua aluna Ana Paula Mendes pela confirmação dos taxa de fungos. A Dra Claudia Gutterres Vilela e Dra Mariana Nunes Cardoso pelo auxílio na identificação dos microforaminíferos. Ao Dr. Mauro Parolin e Me Karen Cristina Silva pela identificação da microesclera de porífero. Ao Dr. Marcelo de Araújo Carvalho pela identificação dos cistos de dinoflagelados. Ao Programa de Pós-graduação em Biodiversidade Vegetal e Meio Ambiente do Instituto de Botânica e Programa de Pós-graduação em Geologia da Universidade Federal do Rio de Janeiro, pelo auxílio técnico-administrativo durante a execução da pesquisa. A FAPESP pela bolsa de Mestrado de CL (processo 2013/01323-8). Ao CNPq pela bolsa de produtividade em pesquisa de CFPL (processo302766/2016-2), bolsa de produtividade em pesquisa sênior de OMB (processo 301992/2017-7), bolsa de doutorado de SYM (processo 141652/2015-2) e pelo apoio financeiro concedido a OMB (edital Universal14/2012, processo 486239/2012-8).

\section{Literatura citada}

Alves-de-Souza, C., Menezes, M., Huszar, V. 2006. Phytoplankton composition and functional groups in a tropical humic coastal lagoon, Brazil. Acta bot. bras. 20: 701-708. 
Araujo, D.S.D., Scarano, F.R., Sá, C.F.C, Kurtz, B.C., Zaluar, H.L.T., Montezuma, R.C.M., Oliveira, R.C. 1998. Comunidades vegetais do Parque Nacional da Restinga de Jurubatiba. In: F.A. Esteves (ed.). Ecologia das lagoas costeiras do Parque Nacional da Restinga de Jurubatiba e do município de Macaé (RJ). NUPEMUFRJ, Macaé, Rio de Janeiro, pp. 39-62.

Araujo, D.S.D. 2000. Análise florística e fitogeográfica das restingas do Estado do Rio de Janeiro. Tese de Doutorado, Universidade Federal do Rio de Janeiro, Rio de Janeiro.

Araujo, D.S.D., Pereira, M.C.A., Pimentel, M.C.P. 2004. Flora e estrutura de comunidades na restinga de Jurubatiba - síntese dos conhecimentos com enfoque especial para a formação aberta de Clusia. pp. 59-76.In: C.F.D. Rocha, F.A. Esteves \& F.R. Scarano (eds.). Pesquisas de longa duração na Restinga de Jurubatiba: ecologia, história natural e conservação. RiMa, São Carlos.

Barth, O.M., Melhem, T.S. 1988. Glossário ilustrado de palinologia. Editora da Universidade Estadual de Campinas, Campinas.

Baseia, I.G. 2005. Some notes on the genera Bovista and Lycoperdon (Lycoperdaceae) in Brazil. Micotaxon 91: 81-86.

Batten, D.J. 1996. Colonial Chlorococcales. In: J. Jansonius, D.C. MacGregor (ed.). Palynology: principles and applications, v. 1. Publishers Press, Chapter 7C, Utah, pp. 191-203.

Bazzle, L.J., Cubeta, M.A., Marks, S.L., Dorman, D.C. 2015. Feasibility of flotation concentration of fungal spores as a method to identify toxigenic mushrooms. Veterinary Medicine: Research and Reports 6: 1-9.

Bennion, H., Simpson, G.L. 2011. The use of diatom records to establish reference conditions for UK lakes subject to eutrophication. Journal of Paleolimnology 45: 469-488.

Belling, B., Cocqut, C., O'Reilly, C.M. 2006. Benthic diatoms as indicators of eutrophication in tropical streams. Hydrobiologia 573: 75-87.

Berglund, B.E. 1986. Handbook of holocene palaeoecology and palaeohydrology. John Wiley, New York.

Bicudo, C.E.M., Menezes, M. (org.). 2006. Gêneros de Algas de Águas Continentais do Brasil - Chave para identificação e descrições. 2 ed., RiMa, São Carlos.

Bicudo, C.E.M., Menezes, M. 2010. Introdução: As algas do Brasil. In: R.C. Forzza, P.M. Leitman, A. Costa, A.A. Carvalho Jr., A.L. Peixoto, B. M.T. Walter, C.E.M. Bicudo, D. Zappi, D.P. Costa, E. Lleras, G. Martinelli, H.C. Lima, J. Prado, J.R. Stehmann, J.F.A. Baumgratz, J.R. Pirani, L.S. Sylvestre, L.C. Maia, L.G. Lohmann, L. Paganucci, M. Silveira, M. Nadruz, M.C.H. Mamede, M.N.C. Bastos, M.P. Morim, M.R. Barbosa, M. Menezes, M. Hopkins, R. Secco, T. Cavalcanti, V.C. Souza. Instituto de Pesquisas Jardim Botânico do Rio de Janeiro. Catálogo de plantas e fungos do Brasil [online]. Instituto de Pesquisa Jardim Botânico do Rio de Janeiro, Rio de Janeiro, pp. 49-60.

Bicudo, C.E.M. 2012. Criptógamos do Parque Estadual das Fontes do Ipiranga, São Paulo, SP, Brasil. Algas, 33: Chlorophyceae (famílias Palmellaceae, Hormotilaceae e Dictyosphaeriaceae). Hoehnea 39: 565-575.
Bove, C.P., Paz, J. 2009. Guia de campo das plantas aquáticas do Parque Nacional da Restinga de Jurubatiba, Rio de Janeiro, Brasil. Série Livros, v. 35. Museu Nacional, Rio de Janeiro.

Brade, A.C. 1940. Contribuição para o estudo da Flora Pteridofítica da Serra do Baturité, Estado do Ceará. Rodriguésia 4: 289-314.

Brenner, W., Foster, C.B. 1994. Chlorophycean algae from the Triassic of Australia. Review of Palaeobotany and Palynology 80: 209-234.

Caliman, A., Carneiro, L.S., Santangelo, J.M., Guariento, R.D., Pires, A.F.P., Suhett, A.L., Quesado, L.B., Scofield, V., Fonte, E.S., Lopes, P.M., Sanches, L.F., Azevedo, F.D., Marinho, C.C., Bozelli, R.L., Esteves, F.A., Farjalla, V.F. 2010. Temporal coherence among tropical coastal lagoons: a search for patterns and mechanisms. Brazilian Journal of Biology 70: 803-814.

Campbell, I.D. 1991. Experimental mechanical destruction of pollen grains. Palynology 15: 29-33.

Cardoso, L.S., Torgan, L.C. 2007. Dinoflagelados em diversos habitats e hidroperíodos na zona costeira do sul do Brasil. Acta bot. bras. 21: 411-419.

Caris, E.A.P., Kurtz, B.C., Cruz, C.B.M., Scarano, F.R. 2013. Vegetation cover and land use of a protected coastal area and its surroundings, southeast Brazil. Rodriguésia 64: 747-755.

Coelho, C.B., Esteves, L.M., Luz, C.F.P. 2017. Fern spore fall in the Parque Estadual das Fontes do Ipiranga (PEFI), São Paulo, Brazil. Grana 56: 273-284.

Costa, A.F., Dias, I.C.A. (orgs.). 2001. Flora do Parque Nacional da Restinga de Jurubatiba e arredores, Rio de Janeiro, Brasil: listagem, florística e fitogeografia. Angiospermas, pteridófitas e algas continentais. Série livros n.8. Museu Nacional, Rio de Janeiro.

Dale, B. 1996. Dinoflagellates cyst ecology: modeling and geological applications. In: Jansonius, J. \& McGregor, D.C. (Eds.). Palynology: Principles and Applications. AASP Foudation, 3: 124901275.

Dale, B. 2001. The sedimentar record of dinoflagelate cysts: looking back into the future of phytoplankton blooms. Scientia Marina 65: 257-272.

Dias, I.C.A. 1997. Chlorophyta filamentosas da Reserva Biológica de Poço das Antas, município de Silva Jardim, Rio de Janeiro: taxonomia e aspectos ecológicos. Tese de Doutorado, Universidade de São Paulo, São Paulo.

Dias, G.T.M., Silva, C.G. 1984. Geologia de depósitos arenosos costeiros emersos - exemplos ao longo do litoral fluminense. In: L.D. Lacerda, D.S.D. Araújo, R. Cerqueira, B. Turcq (eds.). Restingas: origem, estrutura e processos. Universidade Federal Fluminense. Anais do Simpósio sobre Restingas Brasileiras, pp. 47-60. 
Dias, L.C.A., Menezes, M., Sophia, M.G., Souza, C.A., Araújo, A.M., Carmo, B.P., Vianna, C.P. 2001. Parte II - Biodiversidade das Algas Continentais. Capítulo 3. Listagem Taxonômica e Considerações Fitogeográficas. In: Flora do Parque Nacional da Restinga de Jurubatiba e arredores, Rio de Janeiro, Brasil: listagem, florística e fitogeografia. Angiospermas, pteridófitas e algas continentais. Série n. 8. Museu Nacional, Rio de Janeiro. pp. 171- 200.

Duleba, W., Coimbra, J.C.S., Petri, S., Barbosa, C.F. 2005 Foraminíferos, Tecamebas e Ostracodes recentes utilizados como bioindicadores em estudos ambientais brasileiros. In: C.R.G. Souza, K. Suguio, A.M.S. Oliveira \& P.E. Oliveira (eds.). Quaternário do Brasil. Holos, Ribeirão Preto, pp. 176-210.

Ellis, M.B. 1949. Tetraploa. Transactions of the British Mycological Society 32: 246-251.

Ellis, M.B.1971. Dematiaceous Hyphomycetes. Commonwealth MycologicalInstitute, Kew, Surrey, England.

Elsik, W.C. 1981. Palynology short course: fungal palynomorphs. Universidade Estadual de Louisiana, Baton Rouge.

Elsik, W.C. 1992. The morphology, taxonomy, classification and geologic occurence of fungal palynomorphs. A shortcourse presented under the auspices of the American Association of Stratigraphic Palynologists, Houston.

Elsik, W.C. 1996. Fungi. In: J. Jansonius \& D.C. McGregor (eds.). Palynology principles and applications. American Association of Stratigraphic Palynologists Foundation, Publishers Press, Dallas, pp. 293-306.

Enrich-Prast, A., Bozelli, R.L., Esteves, F.A., Meirelles, F.P. 2004. Lagoas costeiras da restinga de Jurubatiba: descrição de suas variáveis limnológicas. In: C.F.D. Rocha, F.A. Esteves \& F.R. Scarano (eds.). Pesquisas de longa duração na Restinga de Jurubatiba: ecologia, história natural e conservação. RiMa, São Carlos, pp. 245-253.

Erdtman, G. 1952. Pollen morphology and plant taxonomy. Angiosperms (An introduction to Palynology. I). Almquist \& Wiksell, Stockholm.

Flora do Brasil 2020. 2018. Jardim Botânico do Rio de Janeiro. Disponível em http://floradobrasil.jbrj.gov.br/ (acesso em 22-VI-2018).

Freitas, A.G., Carvalho, M.A. 2011. Esporos e frutificações de fungos holocênicos de testemunho da Lagoa da Ferradura (Armação dos Búzios, Rio de Janeiro, Brasil). Revista Brasileira de Paleontologia 14: 179-188.

Freitas, A.G., Carvalho, M.A. 2012. Análise morfológica e inferências ecológicas de grãos de pólen e esporos (Últimos 8.000 anos) da Lagoa da Ferradura, Armação dos Búzios, RJ, Brasil. Revista Brasileira de Paleontologia 15: 300-318.
Grimm, E.C. 1987. Coniss: a Fortran 77 program for stratigraphically constrained cluster analysis by the method of incremental sum of squares. Computers and Geoscience 13: 13-35.

Guiry, M.D., Guiry, G.M. 2018. AlgaeBase. Worldwide electronic publication. [Date_Format: (Date GetCurrentDate), -DateFormat='\% $\left.{ }^{\prime}{ }^{\prime}\right]$. AlgaeBase. World-wide electronic publication, National University of Ireland, Galway. Disponível em http://www. algaebase.org; searched on [Date_Format: (Date GetCurrentDate),-DateFormat $\left.={ }^{\prime} \% \mathrm{~d} \% \mathrm{~B} \% \mathrm{Y}^{\prime}\right]$ (acesso em 26-VI-2018).

Groot, G.A., During, H.J., Ansell, S.W., Schneider, H., Bremer, P., Wubs, E.R.J., Maas, J.W., Korpelainen, H., Erkens, R.H.J. 2011. Diverse spore rains and limited local exchange shaped fern genetic diversity in a recently created habitat colonized by long-distance dispersal. In: G.A. Groot (ed.). The fate of a colonizer: Successful but lonely? The establishment of inter- and intraspecific diversity in ferns by means of longdistance dispersal, WODAN-project of the Ecology \& Biodiversity Group, Maastricht, pp. 83-102.

Groot, G.A., During, H.J., Ansell, S.W., Schneider, H., Bremer, P., Wubs, E.R.J., Maas, J.W., Korpelainen, H., Erkens, R.H.J. 2012. Diverse spore rains and limited local exchange shape fern genetic diversity in a recently created habitat colonized by long-distance dispersal. Annals of Botany 109: 965-978.

Hooghiemstra, H. 1984. Vegetational and climatichistory of the high Plain of Bogotá, Colombia: Acontinuous record of the last 3,5 Million Years. Cramer, Vadus.

Huszar, V.L.M., Esteves, F.A. 1988. Considerações sobre o fitoplâncton de rede de 14 lagoas costeiras do Estado do Rio de Janeiro, Brasil. Acta Limnológica Brasileira 2: 323-345.

IBAMA - Instituto Brasileiro do Meio Ambiente e Recursos Naturais Renováveis. 2007. Plano de Manejo do Parque Nacional da Restinga da Jurubatiba. Rio de Janeiro.

Imbassahy, C.A.A, Costa, D.P., Araujo, D.S.D. 2009. Briófitas do Parque Nacional da Restinga de Jurubatiba, RJ, Brasil. Acta Botanica Brasilica 23: 558-570.

Jansonius, J., Mcgregor, D.C. 1996. Palynology Principles and applications. American Association of Stratigraphic Palynologists Foundation, Publishers Press, Lawrence.

Jansonius, J., Kalgutkar, R.M. 2000. Redescription of some fungal spores. Palynology 24: 37-47.

Kalgutkar, R.M., Jansonius, J. 2000. Synopsis of fossil fungal spores, mycelia and frutifications. Dallas, American Association of Stratigraphy Palynologists Foundation, Contributions Series 39.

Laubenfels, M.W. 1955. Porifera. In: R.C. Moore, (ed.). Treatise on Invertebrate Paleontology. Part E, Archaeocyatha and Porifera. (Geological Society of America and University of Kansas Press, New York \& Lawrence, Kansas, pp. E21-E112. 
Lellinger, D.B. 2002. A modern multilingual glossary for taxonomic pteridology. The American Fern Society, Washigton D.C.

Limaye, R.B., Kumaran, K P N., Nair, K M., Padmaiai, D. 2007. Non-pollen palynomorphs as potential palaeoenvironmental indicators in the Late Quaternary sediments of the west coast of India. Current Science 92: 1370-1382.

Lorscheitter, M.L. 1983. Evidences of sea oscillations of the Late Quaternary in Rio Grande do Sul, Brazil, provide by palynological studies. Quaternary of South America and Antarctic Peninsula 1: 53-60.

Lorscheitter, M.L., Roth, L. 2013. O Uso da Concentração polínica em interpretações paleoambientais. Anuário do Instituto de Geociências - UFRJ 36: 80-84.

Luz, C.F.P., Barth, O.M. 2002. Palinomorfos indicadores de tipos de vegetação em sedimentos holocênicos da Lagoa de Cima, norte do estado do Rio de Janeiro, Brasil - Monocotyledoneae, Lycopodophyta, Pteridophyta e Bryophyta. Leandra 17: 7-22.

Luz, C.F.P., Nogueira, I.S., Barth, O.M., Silva, C.G. 2002. Differential sedimentation of algae Chlorococcales (Scenedesmus, Coelastrum and Pediastrum) in Lagoa de Cima, Campos dos Goitacazes Municipality (Rio de Janeiro, Brazil). Pesquisas em Geociências 29: 65-75.

Luz, C.F.P., Barth, O.M., Silva, C.G. 2005. Spatial distribution of palynomorphs in the surface sediments of the Lagoa do Campelo lake, North region of Rio de Janeiro State, Brazil. Acta Botanica Brasilica 19: 741-752.

Luz, C.F.P. 2012. Palynology as a Tool in Bathymetry, Bathymetry and Its Applications. In: P. Blondel (ed.). Bathymetry and its Applications. InTech Open Access Publisher, Croatia, pp. 119-148.

Luz, C.F.P. 2013. Deposição subaquática diferencial de pólen e esporos. Anuário do Instituto de Geociências UFRJ 36: 85-91.

Marret, F., Zonneveld, K.A.F. 2003.Atlas of modern organic-walled dinoflagellate cyst distribution. Review of Palaeobotany and Palynology 125: 1-200.

Martin, L., Suguio, K., Flexor, J.M., Dominguez, J.M.L., Azevedo, A.E.G. 1984. Evolução da planície costeira do rio Paraíba do Sul (RJ) durante o quaternário: influência das flutuações do nível do mar. In: Anais do Congresso Brasileiro de Geologia 33: 84-97.

Martin, L., Suguio, K., Flexor, J.M. 1993. As flutuações de nível do mar durante o quaternário superior e a evolução geológica de "deltas" brasileiros. Boletim IG-USP, Publicação especial 15: 1-186.

Martin, L., Suguio, K., Dominguez, J.M.L., Flexor, J.M. 1997. Geologia do Quaternário costeiro do litoral norte do Rio de Janeiro e do Espirito Santo. Serviço Geológico do Brasil \& FAPESP, Belo Horizonte.
McQuoida, M.R.K., Nordberg, K. 2003. The diatom Paralia sulcata as an environmental indicator species in coastal sediments. Estuarine, Coastal and Shelf Science 56: 339-354.

Medeanic, S., Dillenburg, S R., Toldo Jr., E.E. 2001. Novos dados palinológicos da transgressão marinha pós-glacial em sedimentos da Laguna dos Patos. Revista Universidade Guarulhos 6: 64-76.

Medeanic, S., Garcia, M.J., Stevaux, J.C. 2004. A importânica dos palinomorfos de fungos e de algas nas reconstruções paleoambientais por meio de estudos em sedimentos do Alto Rio Paraná, Taquaruçu, MS, Brasil. Revista Universidade de Guarulhos 9: 19-37.

Medeanic, S., Corrêa, I.C.S., Weschenfelder, J. 2007. Palinomorfos nos sedimentos de fundo da Laguna dos Patos, RS. Aplicação nas reconstruções paleoambientais. Gravel 5: 89-102.

Melo, S., Suzuki, M.S. 1998. Variações temporais e espaciais do fitoplâncton das lagoas Imboassica, Cabiúnas e Comprida. In: F.A. Esteves (ed.). Ecologia das lagoas costeiras do Parque Nacional da Restinga de Jurubatiba e do município de Macaé (RJ). NUPEMUFRJ, Macaé, pp. 177-203.

Moreira-Filho, H., Moreira, I.M.V. 1984. Catálogo das diatomáceas (Chrysophyta - Bacillariophyceae) marinhas e estuarinas do estado do Paraná, Brasil. Acta Biológica Paranaense 13: 3-49.

Muehe, D. 2004. Definição de limites e tipologias da orla sob aspectos morfodinâmico e evolutivo. In: Ministérios do Meio Ambiente e do Planejamento, Orçamento e Gestão. Projeto Orla: subsídios para um projeto de gestão, MMA e MPO, Brasília, pp.13-32.

Pacheco, C.M., Bertolli, L.M., Donadel, L., Torgan, L.C. 2016. O gênero Diploneis Ehrenberg ex Cleve (Bacillariophyceae) em marismas do sul do Brasil. Iheringia, Série Botânica 71: 331-355.

Page, C.N. 1979. Experimental aspects of fern ecology. In: A.F. Dyer (ed.). The experimental biology of ferns, Academic Press, London, pp. 551-589.

Pedrão, E., Carvalho, M.A. 2002. Os fósseis da Bacia de Sergipe/Alagoas. Os palinomorfos: palinoforaminíferos. Phoenix 34: 1-5.

Plano de Manejo do Parque Nacional da Restinga de Jurubatiba. Contextualização da Unidade de Conservação. 2007. Instituto Chico Mendes de Conservação da Biodiversidade, ICMBio, Ministério do Meio Ambiente. Rio de Janeiro.

Punt, W., Hoen, P.P., Blackmore, S., Nilsson, S., Le Thomas, A. 2007. Glossary of pollen and spore terminology. Review of Palaeobotany and Palynology 143: 1-8.

Rocha, C.F.D., Bergallo, H.G., Alves, M.A.S., Sluys, M.V. 2004. A restinga de Jurubatiba e a conservação dos ambientes de restinga do estado do Rio de Janeiro. In: C.F.D. Rocha, F.A. Esteves \& F.R. Scarano (eds.). Pesquisas de longa duração na Restinga de Jurubatiba: ecologia, história natural e conservação. RiMa, São Carlos, pp. 341-352. 
Round, F.E., Crawford, R.M., Mann, D.G. 1990. The Diatoms. Biology and Morphology of the Genera. Cambridge University Press, Cambridge.

Salgado-Labouriau, M.L. 2007. Critérios e técnicas para o Quaternário. Edgar Blücher, São Paulo.

Santos, M.G., Sylvestre, L.S. 2001 . Parte I- Biodiversidade das Angiospermas e Pteridófitas. Capítulo 1 - Listagem Taxonômica. Pteridófitas. In: A.F. Costa \& I.C.A. Dias (org.). Flora do Parque Nacional da Jurubatiba e arredores, Rio de Janeiro, Brasil: Listagem, florística e fitogeografia. Angiospermas, pteridófitas e algas continentais. Série livros n. 8. Museu Nacional, Rio de Janeiro, pp. 143-152.

Santos, M.G., Sylvestre, L.S., Araújo, D.S.D. 2004. Análise florística das pteridófitas do Parque Nacional da Restinga de Jurubatiba, Rio de Janeiro, Brasil. Acta Botanica Brasilica 18: 271-280.

Santos, M.G., Araujo, D.S.D. 2007. Lista anotada das pteridófitas das restingas do Estado do Rio de Janeiro, Brasil. Revista Brasileira de Biociências 5: 378-380.

Santos, A., Araújo Carvalho, M.A., de Oliveira, A.D., Mendonça Filho, J.G. 2017. Paleoenvironmental changes and influence on Operculodinium centrocarpum during the Quaternary in the Campos Basin, southwestern Brazil. Journal of South American Earth Sciences 80: 255-271.

Saxena, R.K., Sarkar, S. 1986. Morphological study of Frasnacritetrus Taugourdeau Emend. from tertiary sediments of Himachal Pradesh, India. Review of Palaeobotany and Palynology 46: 209-225.

Scarano, F.R., Duarte, H.M., Franco, A.C., Geßler, A., de Mattos, E.A., Nahm, M., Rennenberg, H., Zaluar, H.L.T., Lüttge, U. 2005. Ecophysiology of selected tree species in different plant communities at the periphery of the Atlantic Forest of SE-Brazil I. Performance of three different species of Clusia in an array of plant communities. Trees 19: 497-509.

Seppä, H., Bennett, K.D. 2003. Quaternary pollen analysis: recent progress in palaeoecology and palaeoclimatology. Progress in Physical Geography 27: 548-579.

Silva, K.C., Menezes, H.R., Parolin, M. 2009. Avaliação da presença de esponjas de água doce nas bacias hidrográficas do rio Formoso e Sem Passo nos municípios de Campo Mourão e Luiziana/PR. In: IV EPCT - Encontro de Produção Científica e Tecnológica, 2009, Campo Mourão. IV EPCT - Encontro de Produção Científica e Tecnológica. Guarapuava - PR: UNICENTRO/Paraná Gráfica Universitária, v. 4, pp. 9-375.

Silva, R.S., Garcia, M.J., Santos, R.A., De Oliveira, P.E., Giannini, P.C.F., Bernardes-De-Oliveira, M.E.C., Medeiros, V.B., Bistrichi, C.A., Fernandes, R.S., Raczka, M.F. 2015. O significado paleoambiental de palinomorfos de fungos em turfas quaternárias do Médio Vale do Rio Paraíba do Sul, SP, Brasil. Revista do Instituto Geológico 36: 1-24.
Smith, A.R., Kreier H, Haufler C.H., Ranker T.A., Schneider, H. 2006. Serpocaulon (Polypodiaceae), a new genus segregated from Polypodium. Taxon 55: 919-930.

Sota, E.R. de La. 1971. El epifitíssimo y las pteridófitas em Costa Rica (América Central). Nova Hedwigia 21: 401-465.

Souza, J.T. 2012. Integração dos estudos de palinofáceis e palinologia com ênfase em dinocistos (cistos de dinoflagelados) em dois testemunhos do Quaternário da região de Cabo Frio, RJ, Brasil. Dissertação de Mestrado, Universidade Federal do Rio de Janeiro, Rio de Janeiro.

Stancliffe, R.P.W. 1989. Microforaminiferal linings: Their classification, biostratigraphy and paleoecology, with special reference to specimens from British Oxfordian sediments. - Micropaleontology 35: 337-353.

Subramanian, C.V. 1971. Hyphomycetes. Monogr. 9. Indian Council of Agricultural Research, New Delhi.

Traverse, A. 1988. Paleopalynology. Unwin Hyman, Boston.

Tryon,A.F., Lugardon, B. 1990. Spores of the Pteridophyta: surface, wall structure, and diversity based on electron microscope studies. Springer-Verlag, New York.

Tryon R.M., Tryon A.F. 1982. Ferns and allied plants with special reference to tropical America. Springer, New York.

van Geel, B. 1976. A paleoecological study of Holocene peat sections based on the analysis of pollen, spores and macro and microscopic remains of fungi, algae, cormophytes and animals. Thesis University of Amsterdam, Hugo de Vries Laboratorium.

van Geel, B. 1978. A palaeoecological study of Holocene peat bog sections in Germany and the Netherlands, based on the analysis of pollen, spores and macro- and microscopic remains of fungi, algae, cormophytes and animals. Review of Palaeobotany and Palynology 25: $1-120$.

van Geel, B., van Der Hammen, T. 1978. Zygnemataceae in Quaternary Colombian sediments. Review of Palaeobotany and Palynology 25: 377-392.

van Geel, B. 2001. Non-pollen palynomorphs. In: J.P. Smol, H.J.B. Birks, W. Last (eds.). Tracking environmental change using lake sediments. Kluwer Academic Publishers, Holanda, pp. 99-120.

van Hoeve, M.L., Hendrikse, M. 1998. A Study of NonPollen Objects in Pollen Slides. The types as described by Dr. Bas Van Geel and colleagues. Utrecht.

Volkmer-Ribeiro, C., Pauls, S.M. 2000. Esponjas de agua Dulce (Porifera, Demospongiae) de Venezuela. Acta Biologica Venezuelica 20: 1-28. 
Volkmer-Ribeiro, C., Parolin, M. 2010. As esponjas. Pp.105-130. In: M. Parolin, C. Volkmer-Ribeiro \& J.A. Leandrini (eds.). Abordagem ambiental interdisciplinar em bacias hidrográficas no Estado do Paraná. Editora da Fecilcam, Campo Mourão.

Wolf, F.A. 1966a. Fungus spores in East African lake sediments. Bulletin of the Torrey Botanical Club 93: 104-113.

Wolf, F.A. 1966b. Fungus spores in East African lake sediments: II. The Journal of the Elisha Mitchell Scientific Society 82: 57-61.

Wolf, F.A. 1967a. Fungus spores in East African lake sediments. V. Mycologia 59: 397-404.

Wolf, F.A. 1967b. Fungus spores in East African lake sediments. VII. Bulletin of the Torrey Botanical Club 94: 480-486.
Wolf, F.A. 1968. Fungus spores in Lake Singletary sediments. The Journal of the Elisha Mitchell Scientific Society $84:$ 227-232.

Wurzbacher, C.M., Bärlocher, F., Grossart, H. 2010 Fungi in lake ecosystems. Aquatic Microbial Ecology 59: 125-149.

Ybert, J.P., Salgado-Labouriau, M.L., Barth, O.M., Lorscheitter, M.L., Barros, M.A., Chaves, S.A.M., Luz, C.F.P., Ribeiro, M., Scheel, R., Vicentini, K.F. 1992. Sugestões para padronização da metodologia empregada em estudos palinológicos do Quaternário. Boletim do Instituto Geológico 13: 47-49.

Zong, Y. 1997. Implications of Paralia sulcata abundance in Scottish isolation basins. Diatom Research 12: $125-150$. 